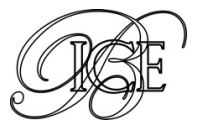

Álvaro Espina*

\section{LA NEGOCIACIÓN COLECTIVA EN ALEMANIA Desarrollo histórico, diseminación continental y reformas}

En este artículo se estudia el sistema alemán de negociación colectiva «dual» desde sus orígenes hasta sus últimos desarrollos, su enorme capacidad de irradiación por toda Europa y la estrategia practicada a largo plazo de diseminación de los costes salariales, desde las grandes empresas hacia las pequeñas y menos productivas y desde la zona occidental hacia la oriental tras la unificación, con la consiguiente destrucción de empleo y desertización industrial en la antigua RDA. Los efectos negativos de este proceso explican la práctica desaparición en Alemania de los convenios colectivos de eficacia general desde la aparición del euro. Un proceso igualmente negativo se registró durante el siglo XXI en la periferia europea que practica la negociación colectiva erga omnes, por lo que resulta imprescindible reformarla.

Palabras clave: convenios colectivos, productividad, competitividad.

Clasificación JEL: J38, J51, J52.

\section{Introducción}

La asimetría existente en buena parte de Europa (especialmente en la Europa del Sur), entre una negociación colectiva salarial uniformista con tarifas sectoriales únicas para grandes sectores y la existencia de la enorme heterogeneidad y jerarquización persistentes de los salarios entre empresas por razón de su tamaño (en una escala máxima que en España va de dos a uno), requiere una explicación que se sitúe más allá de la apelación a las inercias habituales en todo proceso de maduración institucional. Resulta plausible imputar esta asimetría a la diseminación por toda Europa de la estrategia sindical alemana denominada del «látigo salarial para mejorar la productividad». Aunque hoy haya sido parcialmente abandonada (sobre

\footnotetext{
* Consejero Técnico. Dirección General de Política Económica. Versión de junio de 2016.
}

todo en el interior de la propia Alemania) tal estrategia de uniformización salarial fue aplicada en ese país durante el último siglo de forma sistemática. Su influencia sobre toda Europa ha sido notable, ya que el sistema alemán de relaciones industriales es el de trayectoria y continuidad más dilatadas y el que ha tenido mayor influjo en la configuración de estos sistemas en todo el continente a través de una compleja dinámica de difusión institucional en la que ha desempeñado un papel relevante la «presión exterior», al que no ha faltado la «imitación normativa dirigida», practicada a través de diferentes vehículos (el último de los cuales se lleva a cabo a través de la «troica»). No en vano Alemania ha sido considerada como el «tipo ideal» de capitalismo organizado (Lash \& Urry, 1987), que Chandler (1990) identificó y analizó como la tercera variedad del mismo, a la que denominó «capitalismo renano». $\quad \square$ 
Como ha estudiado Wolfgang Streeck en cuatro trabajos penetrantes (2008, 2008b, 2014 y 2016), en buena medida el conjunto de supuestos sobre los que se apoyó este modelo ha desaparecido, pero las consecuencias derivadas del funcionamiento de las instituciones, nacionales y trasnacionales, puestas en pie durante el largo período en que estuvo vigente permanecen. Y, lo que es todavía más preocupante, mientras en Alemania se lleva a cabo el repliegue de estas instituciones (apoyado en parte por la reflexión del propio Streeck), en los países que las adoptaron su reorientación encuentra todavía mayores resistencias porque los individuos tienden a endogeneizar las preferencias sociales que contribuyen al sostenimiento de instituciones a las que el tiempo ha dotado de una pátina de «naturalidad», ayudando a conformar la identidad de quienes las habitan ${ }^{1}$, de modo que el rediseño para adecuarlas al nuevo contexto resulta especialmente costoso por cuanto no se enfrenta a pautas «racionales» de comportamiento, sino que están ancladas en aquello que los agentes individuales consideran su propia identidad individual, y sobre todo colectiva: las vicisitudes por las que atravesó la última reforma francesa son la mejor prueba de ello (y muy especialmente el artículo 2 de la Ley El-Khomri, que se refiere precisamente a la jerarquía normativa de los convenios colectivos) $)^{2}$.

\section{La conformación del sistema alemán de negociación colectiva}

Conviene sintetizar aquí una historia que se remonta a la admisión de la libertad de coalición y del carácter legal de los convenios en la legislación básica de empresas de la

\footnotetext{
1 De acuerdo con la «economía de la identidad» analizada por Akerlof-Kranton $(2000,2010)$, que proporciona pautas de «racionalidad" y utilidad específicas, como pone de manifiesto el estudio de la economía de la educación realizado por ellos mismos en 2002.

2 Véase http://www.lemonde.fr/les-decodeurs/article/2016/05/26/ loi- travail-la-bataille-de-l-article-2 $4927240 \quad 4355770 . h t m l$
}

Confederación Alemana del Norte, transmitida al Kaiserreich tras la unificación de 1871. Una vez superada la etapa de interrupción causada por la prohibición de la acción colectiva y del partido socialdemócrata entre 1878 y 1890, la negociación colectiva prosperó rápidamente, especialmente en la imprenta y la construcción, sectores dominados por empresas pequeñas y medianas que soportaban una fortísima competencia derivada del excedente de trabajo rural, con salarios casi de subsistencia, como corresponde al modelo clásico de desarrollo económico estudiado por Arthur Lewis ${ }^{3}$. Los objetivos de esta primera etapa negociadora, que llega hasta 1914, se centraron en realizar «acuerdos organizativos» de los sindicatos con los empresarios de todas esas ramas -en las que predominaban estructuras de tipo familiar-, por los que las empresas admitían contratar solo mano de obra sindicada, evitando competir entre ellas por bajos salarios, y los sindicatos dirigían sus esfuerzos a afiliar al mayor número de trabajadores, con la condición de que solo aceptasen ser empleados por empresarios que abonasen el salario acordado.

Esta era una estrategia win/win, porque los sindicatos conseguían sus propósitos sin perjudicar a los empresarios, al impedir la «competencia desleal» por los bajos salarios, bloqueando a los free-riders a través de la afiliación masiva, como analizó Philippe C. Schmitter (1974) en sus trabajos sobre el corporatismo (denominado con este anglicismo para diferenciarlo de los corporativismos autoritarios), en que se percibía también una $\triangleright$

\footnotetext{
3 En Alemania la transición desde la economía preindustrial comenzó en 1820 y dio lugar a un largo período de crecimiento de la desigualdad (el ramal ascendente de la «curva de Kuznets») que se prolongó durante todo el siglo y sirvió de soporte a las ideas de Marx sobre el papel del excedente de mano de obra en el capitalismo. Ese modelo quedó superado en 1900, fecha que parece encontrarse en la frontera de la "etapa clásica». La acción sindical pudo acelerar la culminación del proceso. Véase Imperial Germany as an Example of Industrialization under Labour Surplus Conditions, capítulo I, de Grant (2005).
} 
comunidad de intereses entre sindicatos y pequeños empresarios (incapaces de autoorganizarse, dada la competencia de corte walrasiano existente entre ellos) ${ }^{4}$.

Esta modalidad de «corporativismo sectorial» no logró penetrar en las grandes empresas antes de la Primera Guerra Mundial. En cambio, el contexto revolucionario posbélico impulsó el Acuerdo de la Comunidad Central de Trabajo (Zentralarbeitsergemeinschaft: ZAG), de 15-XI-1918, entre Hugo Stinnes, líder de la industria siderometalúrgica (ya considerablemente cartelizada) y Carl Legien, líder de los sindicatos socialdemócratas (ADGB), reconociendo el derecho sindical a organizarse en las fábricas, como mal menor respecto a la opción revolucionaria comunista. AI ZAG siguió la Ley de Negociación Colectiva (23-XII-1918), impulsada por los socialdemócratas, que otorgó carácter legalmente vinculante a todos los acuerdos colectivos, iniciando con ello un tipo de actuación en que los arreglos corporatistas dirigidos por los sectores cartelizados sustituían a la acción del Estado (algo que enseguida se transmitiría a Francia a través del «Comité des Forges») y apoyaban la planificación económica realizada desde el Ministerio de Economía. Mientras tanto, las cláusulas sociales del Tratado de Versalles accedieron a la reivindicación obrera clásica de la jornada de ocho horas en Francia y Alemania y dieron pie a la fundación de la OIT para extender esa conquista a todos los miembros de la futura Sociedad de Naciones, tratando con ello de impedir el «dumping social» (Maier 1988) ${ }^{5}$, algo que se convirtió después en un rasgo secular, actuando la OIT como herramienta trasnacional central de la «imitación normativa dirigida» 6 .

\footnotetext{
4 Tema central de toda su obra, como reza en el discurso de entrega del Nobel de Ciencia Política: http://skytteprize.statsvet. uu.se/LinkClick.aspx?fileticket=1bzQoQq1U\% 2FM\%3D\&tabid=1953 \&language $=s v-S E$. Véase su síntesis en La concertación social en perspectiva comparada (Espina, Comp, 1991).

5 Véase mi interpretación del proceso en Armonización de intereses versus lucha de clases, capítulo introductorio de Espina, Comp. (1991).

6 Ya que, aunque la ratificación de los Convenios OIT sea voluntaria para los países individuales, con frecuencia ratificarlos ha sido requisito obligado para participar en procesos de integración trasnacional.
}

La Constitución de Weimar, de 11-VIII-1919, reconoció el derecho a «crear asociaciones para la protección y mejora de las condiciones de trabajo y económicas», junto a la «libertad de coalición", y en su desarrollo se creó el sistema alemán de tribunales especiales de trabajo, de carácter mixto (imitados más tarde por los jurados mixtos de la República Española), presididos por un juez profesional, y se adoptó la Ley de Comités de Establecimiento, de carácter unitario (Betriebsrätegesetz: $B R G$ ) para centros con más de 20 empleados (4-II-1920). Los BRG eran completamente independientes de los sindicatos, pero fueron estos últimos quienes se ocuparon de estructurar la regulación colectiva supraempresarial a través de acuerdos regionales y/o nacionales con las asociaciones de empresarios fijando tarifas mínimas que podían ser extendidas por el ministro de Trabajo a toda la rama, independientemente del nivel de afiliación de los firmantes, declarándolos «de aplicación general» (de acuerdo con la Ley de 1918). En todo este proceso las pequeñas y medianas empresas, los sectores económicos menos dinámicos y/o cartelizados y los desempleados o la población inactiva (y las mujeres) fueron frecuentemente olvidados. En cambio los BRG se ocupaban de negociar todo lo relativo a la organización y el empleo en el interior de los centros de trabajo. Tal es la urdimbre de la «negociación colectiva dual».

Esta fue la teoría, pero con la inflación galopante de comienzos de los años veinte se introdujo el arbitraje obligatorio del Gobierno para fijar salarios en ausencia de acuerdo (sin que nadie protegiese contra la inflación a los sectores no afectados por los arreglos corporativistas, que se radicalizaron). El intento de manipulación de esta prerrogativa por unos y otros acabó vaciando de contenido la autonomía colectiva salarial antes de que el canciller Brüning la aboliese en 1931 "para resolver la depresión" y de que el nazismo disolviese los sindicatos, substituyéndolos por una «Comunidad de Trabajo $\triangleright$ 
del Reich» en cada sector (unidas todas ellas en el Frente Alemán de los Trabajadores: DAF). Se obligó también a todas las asociaciones empresariales en cada rama a fusionarse en una Confederación Industrial Unitaria, situando entre unas y otras a un «mediador en el trabajo», encargado de fijar las tarifas en diálogo con el ministerio.

Todo ello reproducía a grandes rasgos el Patto di Palazzo Vidoni (2-X-1925) y la Ley Rocco (3-IV-1926) por los que Mussolini llevó a cabo la plena corporativización del sistema de trabajo italiano (que sería imitada después por el corporativismo sindicalista de Franco). Dado el olvido en que el sistema anterior había incurrido hacia los sectores económicos menos dinámicos, ampliamente mayoritarios, los arreglos corporativistas de los fascismos tuvieron su mejor acogida entre las capas medias, las pymes, los agricultores y los desempleados, creándose también «frentes» juveniles y femeninos con los que proporcionar actividad no laboral a los grupos no integrados en la producción (a los que se preparaba para una guerra considerada más o menos inminente).

Las amalgamas organizativas realizadas por el nazismo facilitaron durante la segunda posguerra la reorganización de los interlocutores sociales alemanes en grandes organizaciones sectoriales muy centralizadas. La normativa que refundó el sistema en la República Federal (RF) se apoyó en cuatro pilares: la Ley Fundamental, las Leyes de Codeterminación (de 1951 y 1976), la Ley de Organización de los Centros de Trabajo (de 1952 y 1972) -que recreó los comités de centro (BVG)-, y la Ley de Acuerdos de Negociación colectiva, de 1949, que otorgó amplias facultades de autorregulación, utilizadas enseguida para complementar las reglas de funcionamiento del sistema a través de convenios y prácticas consensuadas. Se reprodujo también el sistema de tribunales de trabajo de Weimar, completándolo con una especie de tribunal supremo, el Tribunal
Federal de Trabajo (BAG), nombrado directamente por el ministro de Trabajo (generalmente entre jueces) ${ }^{7}$, cuyas interpretaciones se encargarían de completar una legislación laboral heterónoma que todos los Gobiernos han tratado de minimizar para «respetar la autonomía colectiva», perdida durante el nazismo.

Quien lideró la negociación colectiva en el conjunto de la RFA, sirviendo de avanzadilla para las negociaciones en el resto de los sectores mediante una estrategia sindical de «sector pautador ${ }^{8}$, fue la IG Metall de la DGB. Esta estrategia se materializó en el logro de grandes acuerdos salariales sectoriales, aplicados y desarrollados después en las empresas. El primero (Convenio Marco Salarial I) data de 1948 y fue renovado en 1953. La culminación del proceso se produjo con el Convenio Marco Salarial II, que fue objeto de un largo período de negociación en 1972, tras un cuatrienio especialmente conflictivo, un arbitraje y una nueva serie de huelgas en las regiones estratégicas de WN/BN y $\mathrm{RNW}^{9}$ para imponerlo y que entró finalmente en vigor el 1 de noviembre de $1973^{10}$.

El acuerdo supuso la plena implantación de la estrategia del «látigo de los salarios para mejorar la productividad», que se venía aplicando durante el decenio anterior a las crisis del petróleo, cuando las empresas funcionaban a plena capacidad y la República Federal había alcanzado el pleno empleo ${ }^{11}$, enfrentándose a una grave escasez de mano de obra $\triangleright$

\footnotetext{
7 Véase el excelente estudio histórico El marco legal de las relaciones industriales en la República Federal, capítulo 2 de Marcovits (1988).

8 También imitada en España como estrategia clandestina por el sindicalismo no oficial durante los años sesenta y setenta, tras el aprendizaje realizado por los trabajadores emigrantes. Véase Paricio (1985).

9 Württemberg Norte/Baden Norte y Renania del Norte-Westfalia.

10 Ibíd, pp. 327-334.

11 En 1973 el desempleo no superaba en las principales zonas metalúrgicas el 1 por 100 de la población activa. En 1974, el 2,5 por 100 (Ibíd, p. 335). En el conjunto de la RFA, durante los años sesenta, el desempleo solo subió del 1 por 100 durante el bache de 19671968. La tasa era del 1,3 por 100 en 1973 pero con la primera crisis del petróleo ascendió hasta 4,7 por 100 en 1975, y con la segunda crisis del petróleo llegaría a situarse en 7,6 por 100 en 1982 (p. 625).
} 
que producía fuertes tensiones migratorias (lo que elevaba la heterogeneidad y la discriminación laboral, rompiendo los lazos tradicionales de solidaridad corporativa). En tales condiciones, forzar el crecimiento de la productividad a través de la elevación de los salarios mínimos en todos los sectores y de la extensión de las condiciones de trabajo y remuneración desde las empresas más productivas a las menos eficientes en cada sector (en un contexto de concurrencia internacional limitada) forzaba la selección evolucionista, la desaparición de empresas marginales y la transferencia de fuerza de trabajo hacia las empresas más competitivas, que tenían «hambre de brazos».

Por mucho que el discurso sindical y socialdemócrata sostuviese entonces que esta política elevaba la productividad en las empresas menos eficientes, la realidad era que la mejora de la productividad agregada se derivaba del «efecto composición» dentro de los propios sectores, de carácter darwinista, y de la trasferencia de trabajo desde los sectores rural y de servicios tradicionales hacia el de servicios modernos y las manufacturas, al igual que había venido ocurriendo en EEUU (Broadberry, $1998)^{12}$, y ocurrió después en España ${ }^{13}$. En un contexto en que la escasez de oferta de trabajo provocaba fuertes tensiones inflacionistas (y de atracción de migraciones internacionales), esta estrategia sindical, instrumentada a través de los convenios estatales y nacionales de rama, resultó complementaria de la política monetaria de control de la inflación (al expandir la oferta

\footnotetext{
12 Estrategia salarial defendida en el entonces denominado «modelo Alemania», del SPD, consistente precisamente en «salarios altos y negociados para toda la industria». El director de la Fundación Friedrich-Ebert en España, Michael Ehrke (2000), analizó el abandono de esta estrategia por la «tercera vía « de la socialdemocracia alemana, bajo el canciller Schröder.

13 Estudié por primera vez este proceso en Espina (1978). También en Cuaderno de Documentación 102.1 (11-VI-2014) http://ima genesbibliotecacentral.minhap.gob.es/pdfpublicaciones/Literaturagris/ cd102-1_2014.pdf). Pero en España esta estrategia no conducía al pleno empleo sino a la emigración exterior, complementando la estrategia alemana y de otros países centrales, que atravesaban igualmente por una etapa de hambre de brazos (Kindleberger, 1967) y venía a contribuir al despegue español aportando flujos de remesas, que reducían al mismo tiempo el estrangulamiento de financiación externa.
}

de trabajo), de la política macroeconómica de impulso al crecimiento y de la política de control de las migraciones (y de reducción de la discriminación por razones de origen y de género), produciendo elevaciones del salario medio que atrajeron población económicamente inactiva, impulsando la elevación de la tasa de actividad femenina.

\section{Ascenso y ocaso de la estrategia alemana del «látigo salarial para aumentar la productividad»}

Las dos crisis del petróleo y la conexión entre las crisis de 1975 y 1982 ya produjeron fuertes divisiones sobre la continuidad de la estrategia, tanto dentro de los sindicatos como de las asociaciones empresariales, dependiendo estas últimas de la prosperidad relativa de las distintas ramas de las manufacturas (con el sector de automoción liderando el proceso salarial centralizado y el de construcción de maquinaria tratando de frenarlo). La crisis de la estrategia tradicional se agudizó sobre todo cuando la aceleración del cambio tecnológico empezó a imponer su ley en el mercado de trabajo y la preocupación por el desempleo, la racionalización y la descualificación derivadas de aquel empezó a instalarse entre los trabajadores. A ello vino a unirse la rápida internacionalización del mercado mundial del acero, con el predominio de japoneses y coreanos y la irrupción de la producción altamente especializada de los pequeños productores «Bresciani».

El proceso de reestructuración no había hecho más que empezar, pero a lo largo del decenio iban a ir despareciendo sectores enteros de actividad que habían sido los tradicionalmente dominantes en la economía alemana (y en la de otros países centroeuropeos, como Austria y Bélgica). Aunque inicialmente el impacto se dejó sentir principalmente sobre el trabajo descualificado y semicualificado, la llegada $\triangle$ 
de las nuevas tecnologías terminó por afectar también al trabajo cualificado. En 1985 la tasa de desempleo se aproximaba ya al 11 por $100^{14}$. Esto es, en diez años se había pasado del agotamiento de la fuerza de trabajo disponible a una situación de superabundancia y desempleo. La estrategia de látigo salarial no respondía ya a las demandas laborales (centradas en la reestructuración y la transición entre diferentes empleos) y resultaba ineficiente desde el punto de vista macroeconómico, acelerando un cambio estructural ya bastante dinámico de por sí $^{15}$, elevando innecesariamente la concentración empresarial y el desempleo. La obsesión por la uniformidad salarial dejó paso durante el decenio de los ochenta a políticas y estrategias de diferenciación salarial (y a negociaciones a la baja, «ofensivas» o «de concesión», para defender el empleo y dilatar algo el tiempo de transición) que se fueron abriendo paso a contracorriente, a través del leit motiv de «restaurar la competencia entre los trabajadores», consustancial a la desaparición de los sistemas de organización taylorista (que sobrevivían en las viejas instituciones laborales), para dar paso a actividades más complejas en innovación y valor añadido (Sengenberger, 1988 y 1991). Pero las resistencias al cambio fueron enormes, aunque a finales del decenio la tendencia a formar «coaliciones de productividad» ya era clara, y también el intento sindical de neutralizarla (Windolf, 1989).

Con la llegada de los noventa dos fenómenos vinieron a complicar las cosas todavía más. Frente a la denominada euroesclerosis, la entrada en funcionamiento del mercado único iba a elevar considerablemente la competencia entre las empresas del continente. Además, el

\footnotetext{
14 Según el cómputo de la época; con la sistemática actual habría ascendido al 9,3 por 100 , respecto a la población activa dependiente, y al 8,2 por 100 en relación con la población activa total (véase el Gráfico 4).

15 Entre 1970 y 1996 la productividad/hora creció en Alemania a una tasa anual del 2,9 por 100; siguió creciendo a una tasa del 1,7 por 100 entre 1996 y 2004, reduciéndose a la mitad en 2004-2015 (0,83 por 100: datos primarios tomados de: http://stats.oecd.org/ viewhtml.aspx?datasetcode $\left.=P D B \_L V \& l a n g=e n\right)$. Para España las cifras correspondientes son: 3,3, por 100 y 1,24 por 100 .
}

colapso del bloque soviético dio paso a la unificación alemana y a la integración rápida de sus dos mercados de trabajo ${ }^{16}$. Frente a la alegría mostrada en ambos casos por el empresariado alemán (que consiguió de Helmut Kohl no ratificar los nuevos convenios de la OIT, especialmente el $154^{17}$ sobre negociación colectiva, y el 158 sobre terminación del contrato de trabajo), la conjunción de ambos fenómenos produjo una verdadera conmoción en los sindicatos. Por un lado, la gran heterogeneidad entre los sistemas laborales de los doce Estados miembros los retrotraía a sus orígenes (luchar contra los efectos salariales de las amplias disponibilidades de mano de obra en la periferia), pero ahora el objetivo tradicional de uniformización laboral, de mantenerse, debía extenderse a doce países (y enseguida a muchos más, provocando el síndrome del «fontanero polaco»).

De nuevo fue Schmitter (et al., 1997) quien identificó la fuerza de este miedo como motor para impulsar el «sísifo corporatista», pero ahora a escala verdaderamente europea, tratando de imponer definitivamente la negociación intermedia de carácter sectorial (y no la política de rentas coordinada desde la cúspide, que se había empleado para combatir la inflación) como el modelo vigente en toda Europa ${ }^{18}$, pese $\triangleright$

\footnotetext{
16 Marcovits-Otto, (1991) analizaron en detalle el impacto y efectos de estos dos «frentes del miedo» sobre los diferentes sindicatos, identificando dos posturas, denominadas activista y acomodacionista, cuya implantación en las distintas ramas no se correspondía exactamente con los efectos esperados del proceso de integración europeo sobre el correspondiente sector. Paradójicamente varios sectores previsiblemente «ganadores» en este proceso eran activamente obstruccionistas (como IG Medien, de artes gráficas), mientras que en otros previsiblemente perjudicados o con efectos mixtos predominaban actitudes acomadacionistas. Su conclusión fue que «la ideología, importa».

17 De entre los países no ratificadores de este convenio el más explícito en la explicación de las razones para no hacerlo es Australia, ya que la Fair Work Act sitúa el espacio de la negociación colectiva en la empresa, lo que se considera incompatible con el convenio. Véase ACTU (2015).

18 Véase Glassner-Pochet (2011), Tabla 3: los únicos países europeos en donde la negociación a nivel de empresa individual se imponía sobre la supraempresarial eran los del centro y este de Europa (antiguo Comecom), Malta y Reino Unido. En Francia, antes de la reforma existía predominio de la negociación de empresa, aunque la negociación de rama, de existir, tenía prelación jerárquica. En Bélgica, Finlandia e Irlanda predominaban los acuerdos nacionales (intersectoriales).
} 
a que hacía tiempo que la literatura analítica venía observando la ineficiencia de este modelo de negociación. Este primer frente de los miedos sindicales se encauzó a través de la presión para armonizar los derechos de los trabajadores mediante la «Carta Social Europea» y con una estrategia de activación de las reivindicaciones comunes a través de la Confederación Europea de Sindicatos (CES), tradicionalmente dominada por la DGB, dirigida especialmente hacia la elevación de la presión reivindicativa salarial en los países periféricos, con vistas a proporcionar un colchón competitivo a los del centro $^{19}$. Schulten (2002) presentó nítidamente los elementos de esta estrategia de extensión, que desbordaba las iniciativas de diálogo social y la estrategia previamente adoptada de profundización del protocolo social del Tratado de Maastricht y del Tratado de la UE -limitados a los aspectos «blandos del diálogo social», como las condiciones mínimas de trabajo y de políticas sociales-, para acometer directamente los «asuntos duros» del conflicto distributivo, esto es la fijación de remuneraciones y el tiempo de trabajo, a través de un nuevo sistema europeo de negociación colectiva: la así llamada European trade union coordination approach, que ya no persigue elevar de nivel el ámbito de la negociación sino coordinarlo e interconectarlo a escala europea para «limitar la competencia nacional sobre salarios y costes laborales», articulándolo en tres niveles (Dufresne 2002; Glassner/ Pochet, 2011):

1. Interregional, que cubre solo a un número limitado de países.

2. Sectorial, coordinado por las Federaciones de Industria Europeas (EIFs).

19 Estudié el impacto de todo esto en Espina (2007). En lo que se refiere al contagio de este miedo hacia los sindicatos del sur, véase especialmente el epígrafe 3. Pero el efecto pernicioso de estas dinámicas venía registrándose en España desde mucho antes, propiciando un modelo de desarrollo intensivo en capital (y poco utilizador de empleo), que resultó absolutamente inconsistente con las disponibilidades relativas de factores, como analicé en el Cuaderno de Documentación 102.2 (12-IX, 2014). Disponible en: http://image nesbibliotecacentral.minhap.gob.es/pdfpublicaciones/Literaturagris/ cd102-2_2014.pdf
3. Transnacional, coordinado por la Confederación Europea de Sindicatos (CES-ETUC).

El primero se materializó inicialmente a través de los llamados «acuerdos de Doorn» concluidos en 1998 entre los sindicatos alemanes y los del Benelux (con vistas a la aparición del euro), para coordinar anualmente las políticas sindicales de negociación en esos países. Sintomáticamente estos acuerdos fueron impulsados principalmente por Bélgica, en donde la ley sobre la competitividad de 1996 limitó los aumentos salariales de ese país al promedio de los crecimientos esperados de salarios en los principales socios comerciales (Francia, Países Bajos y Alemania), con el objetivo de que la única forma de elevarlos fuera hacerlo conjuntamente con ellos.

Es precisamente a partir de ese año cuando los costes salariales alemanes experimentaron la gran inflexión en su tendencia de crecimiento, separándose de la de los otros cuatro países y de la del conjunto de la eurozona hasta 2009. El fuerte repunte del crecimiento de las remuneraciones alemanas hasta 1995 (que se registró también en Bélgica) se debió a la asimilación de la unificación, y muy especialmente al fuerte crecimiento salarial impuesto a la Alemania del Este, primero por la conversión del tipo de cambio uno por uno entre los dos marcos, y enseguida por la estrategia de rápida convergencia salarial impuesta por la DGB (como se estudia más adelante), aunque los salarios en la antigua Alemania Federal (que son los que importan para medir la competitividad internacional), crecieron obviamente muy por debajo de lo que muestra la serie de AMECO 20.

Pese a todo ello, Alemania actuó en cierto modo como un ancla para el crecimiento de las remuneraciones nominales de los países $D$

20 El crecimiento de los salarios de Alemania Oriental fue de tal dimensión que en 1992, según las series AMECO, la remuneración media por asalariado de la Alemania unificada ya fue superior a la de la Alemania Federal en 1991 (en torno a 26.000 euros/año). 


\section{Álvaro Espina}

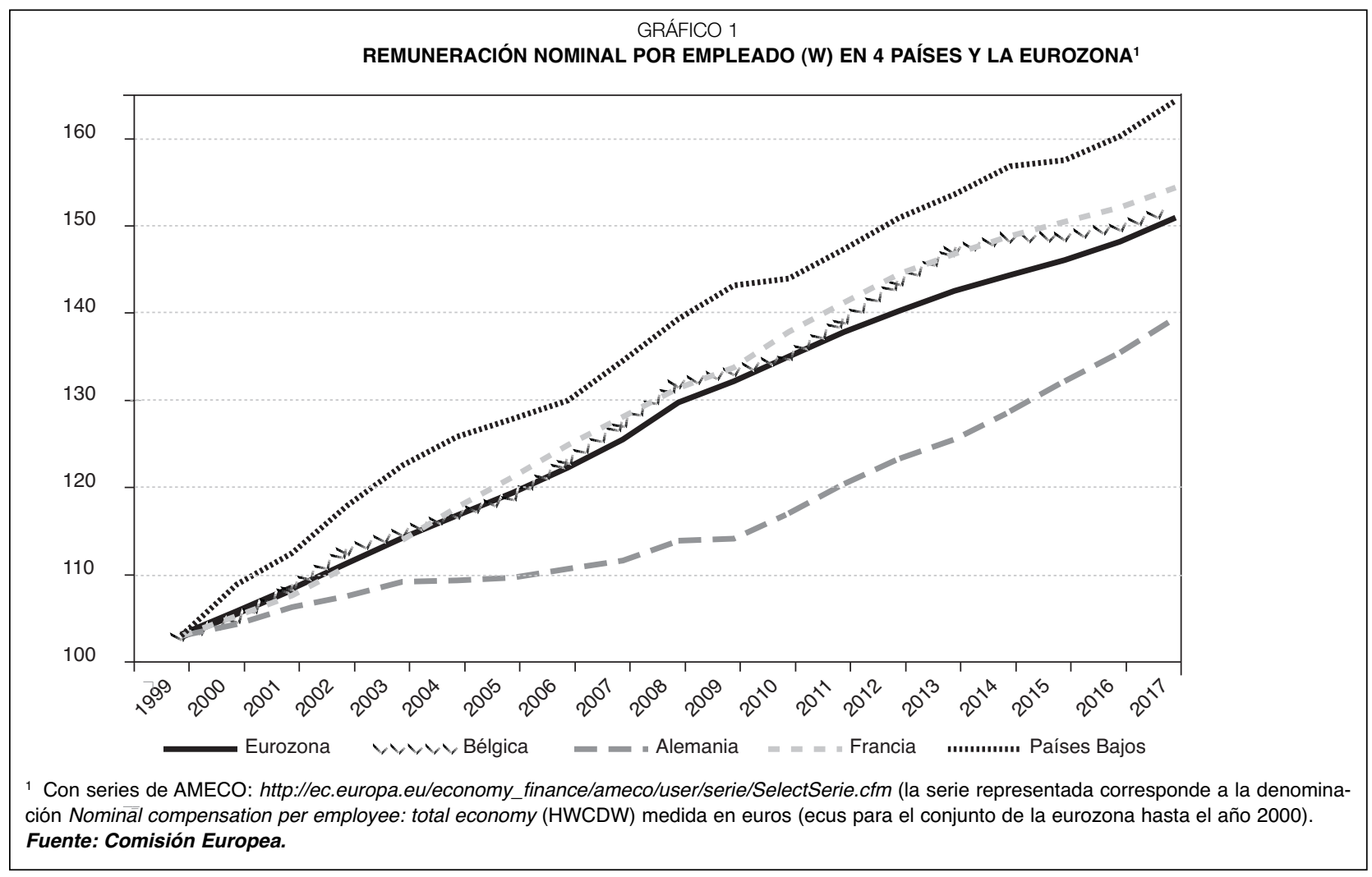

GRÁFICO 2

COSTES LABORALES UNITARIOS (CLU) NOMINALES EN CUATRO PAÍSES Y LA EUROZONA Índices (base $1999=100)^{1}$

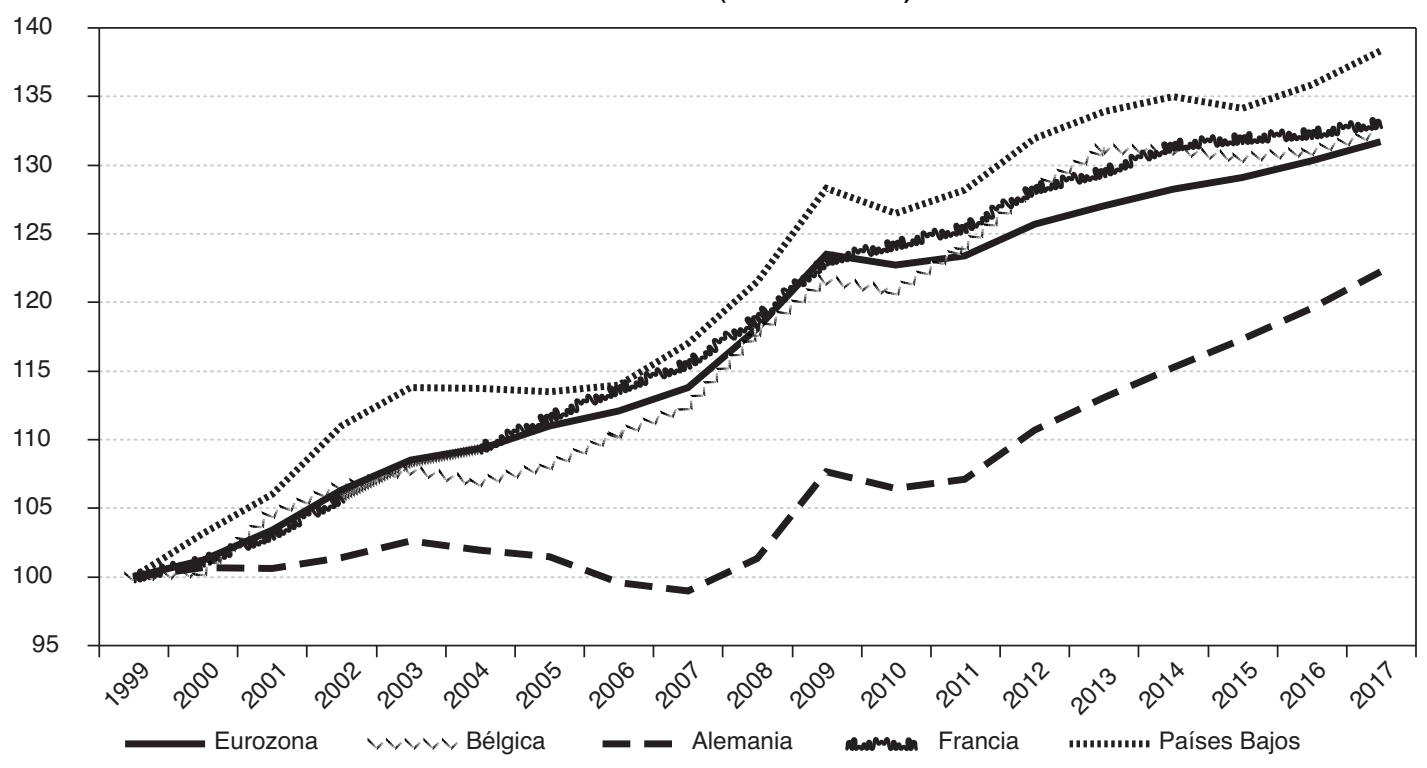

1 Con series de AMECO: http://ec.europa.eu/economy finance/ameco/user/serie/SelectSerie.cfm (la serie representada corresponde a la denominación Nominal unit labour costs: total economy (Ratio of compensation per employee to real GDP per person employed.) (PLCD). Obsérvese que las tasas logarítmicas de variación de las tres variables consideradas (en minúsculas) se relacionan así $c l u=w-p$.

Fuente: Comisión Europea. 
centrales hasta 2009, algo que se observa con especial intensidad en el Gráfico 1 (con base 100 en 1999, año en que se adoptó el euro). En síntesis, mientras en el año 2000 la remuneración media alemana se encontraba próxima y algo por encima de la del conjunto de la eurozona-12 (31,2 frente a 30,3 miles de euros/año), en 2009 la relación se había invertido y ya se situaba en 34,2-37,9. Así, en Alemania la remuneración media había crecido en 3.000 euros, la de Francia había aumentado casi en diez mil, situándose en 44,4 y la belga y la holandesa algo más, situándose en 48,2 y 51,8 , respectivamente.

Una vez descontados los efectos del crecimiento de la productividad $(\mathrm{P})$, este ancla produjo un crecimiento de los costes laborales unitarios nominales (CLU) en Francia y Bélgica (y también en Holanda, aunque en este caso algo superior) alineado en general con el del conjunto de los de la eurozona ${ }^{21}$ (Gráfico 2), que resultaban compatibles, hasta la llegada de la crisis, con el objetivo de un crecimiento de los precios en torno al 2 por 100, cosa que no sucedió en Alemania, lo que puede imputarse al abandono del modelo de negociación colectiva prevaleciente hasta entonces, que formalmente seguía defendiéndose por las instancias sindicales y en la manifestaciones públicas gubernamentales, pero que en realidad estaba cambiando rápidamente, como consecuencia en parte de las reformas del mercado de trabajo de 2002-2005, que redujo el poder relativo de los negociadores sindicales.

No existe un diagnóstico de consenso acerca de la relación de todo ello con las dificultades que experimentaría después la eurozona para mantener el objetivo de inflación, o con la aparición de grandes desequilibrios por cuenta corriente, e incluso de los riesgos de deflación (con la consiguiente amenaza para la integración de

${ }^{21}$ Para estos tres países las tasas de crecimiento de la productivi$\mathrm{dad} /$ hora en los períodos 1970-1996, 1996-2004, y 2004-2015 resultaron bastante similares: 3,$1 ; 2 ; 0,7 ; 3 ; 1,4 ; 0,5$ y 2,3; 1,8 ; y 0,7 por 100 , respectivamente, de modo que las diferencias de CLU se deben sobre todo a los salarios. la UEM) ${ }^{22}$, aunque la relación de todo ello con la reforma laboral y la evolución salarial desde la aparición del euro parece incuestionable ${ }^{23}$.

Los Gráficos 3.A, 3.B, y 3.C (en la página siguiente) sintetizan la evolución de las tres variables básicas - medidas en tasas anuales de variación, a partir de las series AMECO- para el total de la economía durante los tres períodos significativos en estos cuatro países centrales y en la eurozona-12.

En ellos puede observarse que, mientras en Alemania la adopción del euro significó el hundimiento de las tasas de variación de los salarios y de los CLU a la tercera parte de la registrada durante el decenio precedente (después de la unificación), los otros tres países mantuvieron ritmos similares, consistentes con crecimientos de los costes laborales unitarios alineados con el objetivo de crecimiento de inflación. Los desequilibrios de competitividad originados por esta estrategia alemana de empobrecimiento de los vecinos dieron lugar, tras la crisis de la eurozona, a una carrera hacia la recuperación de la misma en estos países mediante la compresión del crecimiento salarial por debajo del 2 por 100 para limitar el crecimiento de los CLU al 1 por 100 (lo que explica el brusco descenso de la inflación y la amenaza deflacionista en la eurozona), mientras Alemania aligeraba la compresión del crecimiento salarial y de sus costes, aunque situándose todavía por debajo del objetivo de inflación del BCE.

\section{La divergencia entre estrategia hacia afuera y práctica interior: las reformas Hartz-Schröder}

En realidad, la iniciativa enunciada por Schulten (2002) no logró ampliar mucho su ámbito después. Pese a la afirmación sindical $\triangleright$

\footnotetext{
22 Para Willem Buiter los problemas no derivan del exceso de ahorro en Alemania, sino del déficit de inversión, tanto en la propia Alemania (mientras exista riesgo de deflación), como en los países con elevadas tasas de desempleo: https://www.linkedin.com/pulse/ german-current-account-surplus-willem- $h$-buiter?trk=mp-reader-card

${ }_{23}$ Para una posición considerablemente ecléctica, véase Kollmann et al. (2014)
} 


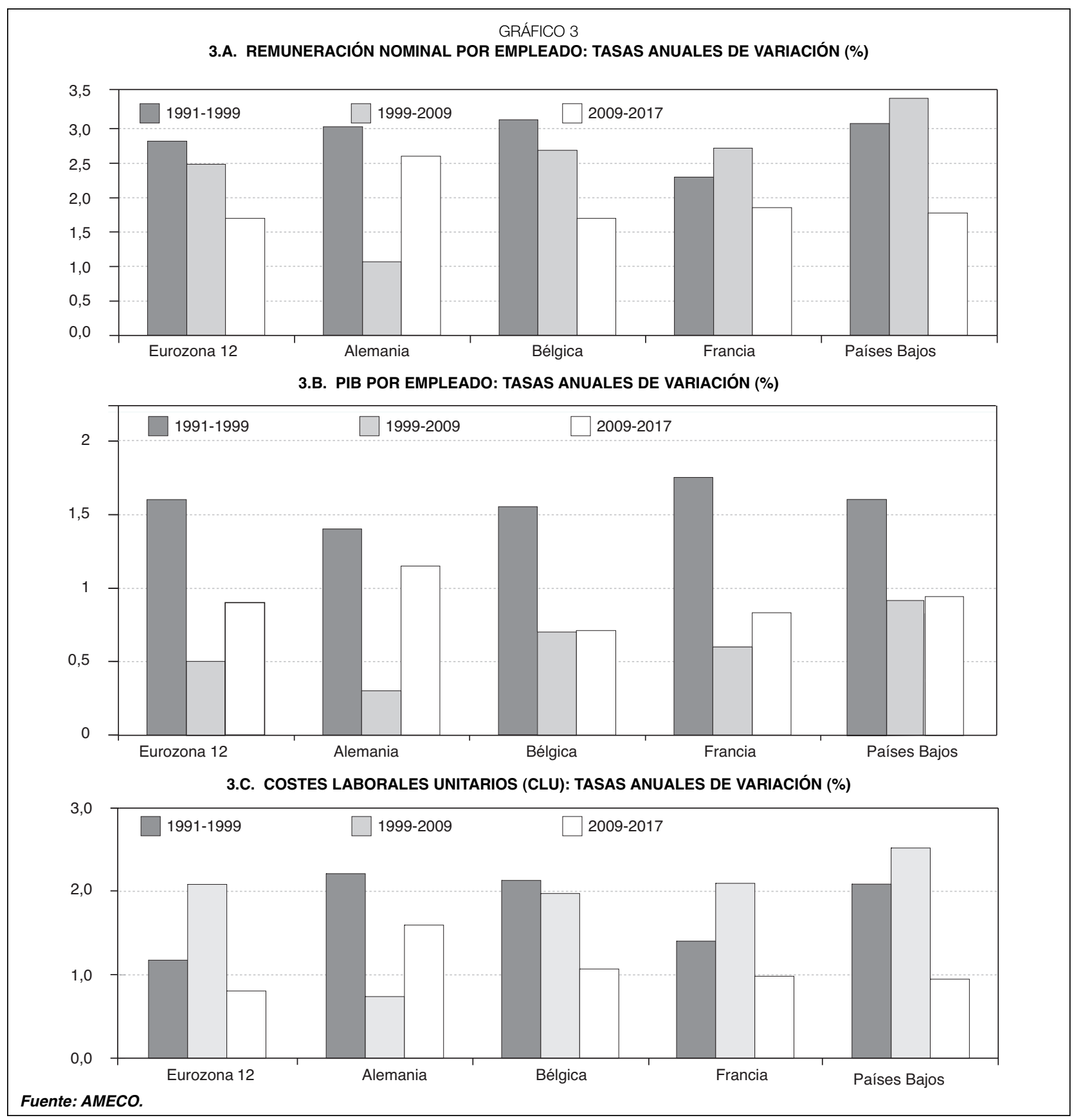

de que los objetivos de crecimiento salarial se mantuvieron ligados a la acumulación de precios al consumo y productividad, los efectos reales de la estrategia efectivamente aplicada han consistido en frenar los crecimientos salariales del grupo de países centrales incluidos en los gráficos anteriores, tratando de vincularlos al ritmo de los alemanes, aunque con escaso éxito, dada la estrategia de moderación extrema aplicada efectivamente por la DGB durante esos años -que quedó muy por debajo de aquellos objetivos-. Sin embargo, esa limitación explica que ninguno de esos países figure entre los que experimentaron crecimientos de salarios nominales y de costes laborales unitarios más anómalos durante la primera etapa del euro, que aparecen más adelante en los Gráficos 6 a 8 .

En aquel mismo nivel interregional, aunque de ámbito sectorial, IG Metal lanzó una iniciativa a escala europea en 1997 que tampoco parece haber tenido mucho efecto, probablemente $\square$ 
porque la propia organización veía lastrada la legitimidad de sus esfuerzos al practicar la DGB durante toda la etapa de expansión una estrategia de búsqueda de competitividad a través de la contención salarial extrema, de modo que tales iniciativas se limitaron a constatar la interacción ya existente entre los distritos trasfronterizos vecinos ${ }^{24}$. Han existido otras iniciativas de este tipo impulsadas por IG Química-energía e IG Construcción, limitadas en la práctica al intercambio de información periódica y al establecimiento de principios comunes, tan ambiciosos como parcos en la consecución de objetivos, excepto en los casos en que se han registrado fusiones y adquisiciones trasnacionales, siempre a iniciativa alemana, para tratar de limitar la competencia salarial de sus vecinos.

Por lo que se refiere al nivel sectorial, fue también la Federación Europea del Metal (EMF) la que desplegó una acción más intensa a través de dos instrumentos: las "orientaciones comunes para la negociación colectiva europea», y el establecimiento de «estándares mínimos de la EMF» (con jornada semanal de trabajo de 35 horas y anual de 1.750 , límites a la flexibilidad, etcétera) dirigidos ambos a evitar la «concurrencia a la baja de las condiciones de empleo", llegando a poner en pie una estructura institucional de supervisión sindical cuidadosamente diseñada con vistas a garantizar la aplicación de los principios de transmisión de la inflación y la productividad a los salarios (de modo que con la moneda única los países más tradicionalmente inflacionistas 0 aquellos que experimentan ciclos fuertemente expansivos pierden competitividad rápidamente, cualquiera que sea su nivel de empleo y/o desempleo). El decenio que precedió a la llegada del euro sirvió para implantar todas estas doctrinas a través de las Collective Bargaining Conferences celebradas desde entonces, especialmente las de 1993, 1996, 1998 y 2001.

\footnotetext{
${ }^{24}$ El cuadro de redes trasfronterizas de negociación colectiva en distritos de IG metal aparece en Schulten, 2002, Tabla 2.
}

La difusión de este esquema hacia doce grandes federaciones sindicales fue estudiada también por Schulten (2002, Tabla 3). Y en lo que respecta al nivel transnacional, coordinado por la Confederación Europea de Sindicatos (CES-ETUC), en su $9^{\circ}$ congreso celebrado en el verano de 1999 se estableció -como cuarto pilar del «Sistema Europeo de Relaciones Industriales»-25 una «política coordinada europea de negociación colectiva», centrada en su política solidaria europea de salarios (pay policy), que incluye:

- Una garantía para los trabajadores de participación decente en los ingresos.

- Impedir el peligro de «dumping social».

- Impedir la desigualdad creciente de ingresos en algunos países.

- Contribuir a la reducción de desigualdades en las condiciones de vida.

- Contribuir a la aplicación efectiva del principio de igualdad de trato entre sexos.

Resulta sorprendente que en todo este ideario no aparezca el más mínimo objetivo de empleo, como tampoco aparecía en las «orientaciones europeas para la coordinación de la negociación colectiva», adoptadas por el comité ejecutivo de la CES-ETUC en diciembre de 2000 , con el objetivo de garantizar una negociación colectiva racional, que suponía:

- Los aumentos de los salarios nominales deben exceder como mínimo el nivel de la inflación, maximizando la proporción de la productividad asignada al aumento de los salarios brutos para garantizar un mejor equilibrio entre salarios y beneficios.

- El remanente de los aumentos de productividad debe asignarse a otros objetivos de la agenda de negociación, de tipo cualitativo.

- Los salarios del sector público y privado deben aumentar en paralelo.

Todo ello perseguía «producir una convergencia hacia arriba de los niveles de vida en $\triangleright$

25 Junto a la «normativa social», el «diálogo social» y los «comités de empresa europeos». 
Europa, y particularmente dentro de la eurozona», en donde los salarios son fácilmente comparables. Al servicio de este programa, la CES ha ido poniendo en funcionamiento un complejo marco institucional con seis niveles, representados por Glassner/Pochet (2011, Tabla 1).

Mientras todo esto ocurría en el sector de relaciones internacionales de los sindicatos alemanes y entre sus funcionarios destacados, en la CES el miedo a la nueva concurrencia dentro del mercado único (y enseguida en la eurozona) había llevado a la DGB a renunciar de facto (en Alemania occidental), ya desde 1993, al principio según el cual la inflación y los avances de la productividad deben transferirse a los salarios ${ }^{26}$, sin abandonar por ello la estrategia europea de armonización salarial (a través de la negociación colectiva y, si no fuera posible, a través del establecimiento de un salario mínimo europeo, con carácter vinculante). Además, dentro de la propia Alemania la cobertura de la negociación cayó sustancialmente. Esta estrategia bifronte fue teorizada por el máximo representante de la escuela alemana de sociología política, especializado en el análisis del neocorporatismo -Wolfgang Von Streeck, convertido en asesor del canciller Schröder - quien escribió un artículo paradigmático en 1999 en el que afirmaba que la meta principal de las políticas sociales alemanas hasta el año 2010 no debía ser aumentar los salarios sino cubrir el déficit de siete millones de empleos existente en el país unificado, sacrificando a este objetivo otras aspiraciones ${ }^{27}$. Traducido de manera rudimentaria, el mensaje contrario a la política de armonización salarial era perfectamente claro:

«Al realizar comparaciones internacionales se observan vínculos muy claros a escala

\footnotetext{
26 Véase Erne (2008), p. 100.

27 Véase Wolfgang Von Streeck \& Rolf Heinze «Programa Schröder: An Arbeit fehlt es nicht», SpiegleOnline 10.05.1999, disponible en: http://www.spiegel.de/spiegel/print/d-13220370.html. El déficit no computa solo el desempleo (que era de 4,1 millones, 1,5 de ellos en la antigua RDA), sino la baja tasa de actividad y la población desanimada.
}

macroeconómica entre el nivel de empleo en el sector privado de servicios y las diferencias salariales entre individuos y sectores industriales. Si la productividad media nacional (o incluso, la de la industria metalúrgica y eléctrica) sirve como pauta para la formación de los salarios en toda Alemania la creación de nuevos puestos de trabajo en el sector servicios se verá obstaculizada. Esa es la razón de que en casi todos los países europeos los diferenciales de productividad inter e intrasectoriales se tomen cada vez más en cuenta para la fijación de los salarios. Con ello aparecen nuevas posibilidades de creación de empleo de menor cualificación en los servicios a través de la flexibilidad salarial»".

Nueve años más tarde, a punto de cumplirse la fecha término de aquel programa, (Streeck, 2008) consideraba que no se trataba de un simple objetivo a plazo determinado, sino de un cambio estructural, derivado de la necesidad de adaptarse al nuevo contexto de incertidumbre, que obliga a una reestructuración profunda de las instituciones sociales posbélicas, en busca de una mayor eficiencia económica:

«A medida que la competencia internacional y la volatilidad de los mercados han erosionado la rigidez y el carácter excesivamente inflexible de las reglas laborales, el equilibrio de poder ya no se encuentra en las instituciones posbélicas de acción colectiva. De cara al futuro, solo un cambio drástico de las condiciones demográficas podría permitir suavizar los imperativos de eficiencia y maximización de la utilidad para dejar un mayor espacio a la política de derechos del que ahora existe".

Toda esta reflexión significaba un cambio completo de orientación que se materializó en el conjunto de reformas patrocinadas por la comisión de quince miembros ${ }^{28}$ de variada procedencia, presidida por Peter Hartz (director $\triangleright$

\footnotetext{
28 Creada por el canciller Schröder tras el fracaso de la «Alianza para el empleo» (Bündnis für Arbeit), de carácter tripartito, ensayada durante su primer mandato entre 1998 y 2001.
} 
de personal de Volkswagen, que le dio nombre, aunque oficialmente se la denominó «Comisión para modernizar los servicios del mercado de trabajo»), diez de cuyas trece recomendaciones (o «módulos») -hechas públicas en agosto de 2002-, se plasmaron en un conjunto de iniciativas que Kemmerling y Bruttel (2005) sintetizaron en tres pilares:

- La introducción de las ideas modernas de Public management en el Servicio Público de Empleo (PES, de carácter federal, con 90.000 empleados, diez direcciones regionales y 180 oficinas locales).

- Cambios fundamentales en el seguro de desempleo.

- Un variado conjunto de medidas dirigidas a elevar la participación en el mercado de trabajo (la tasa de actividad) y la búsqueda activa de empleo a través del leit motiv «que el trabajo compense» (making work pay).

Su concreción se realizó en un conjunto de leyes que entraron en vigor en tres oleadas entre el 1 de enero de 2003 (Hartz I y Hartz II), y la misma fecha de 2004 (Hartz III) y de 2005 (Hartz IV). La primera oleada introdujo agencias de trabajo temporal y un «bono de formación» (training vaucher). Además endureció la definición de «empleo adecuado» y estableció un régimen de sanciones más flexible que el previamente vigente (Hartz I). Por otra parte, se adoptó un nuevo sistema de tributación y bonificaciones para incentivar los trabajos de muy corta duración (Mini-Jobs) y el autoempleo (Hartz II). Los trabajos con ingresos por debajo de 400 euros quedaron exentos de tributación y cotización para el empleado (y cotizan entre el 4 y el 21 por 100 hasta el umbral de 800 euros), abonando el empleador una tarifa plana de 25 por 100 por todos los conceptos.

La segunda oleada (Harz III), se centró en la reforma del sistema de colocación cambiando la estructura del PES, anteriormente regido por un comité administrativo tripartido de 50 personas y un consejo ejecutivo honorario cooptado por los interlocutores sociales. La reforma transformó el consejo administrativo en un consejo de supervisión (con facultades fundamentalmente informativas) y la gestión se confió a un ejecutivo profesional y a un Consejo de Administración con mandato quinquenal que fija los objetivos a conseguir (negociados entre los ministros de Economía y de Trabajo). El nuevo PES dispone de plenas facultades para el cumplimiento de su mandato sin interferencias políticas, al tiempo que se confiere un amplio nivel de autonomía a las oficinas de distrito.

El propósito del nuevo sistema de colocación consiste en proporcionar asistencia personalizada a los buscadores de empleo, con ayuda de la elaboración de su «perfil» y de la identificación de las necesidades individuales de capacitación mediante la comparación del perfil individual con los requerimientos estandarizados de capacidades en el mercado de trabajo. Todo ello llevado a cabo desde los Job Centers, que concentran las competencias de gestión de todos de los servicios relacionados con el mercado de trabajo, de asesoramiento y apoyo para los servicios de protección (diferenciado para los jóvenes), la oficina de apoyo a la vivienda y los servicios de recuperación de la drogadicción. En paralelo, se proporcionan medios para que los empleadores canalicen la cobertura de sus vacantes a través de los Job Centers.

Uno de los retos del nuevo PES consiste en la contratación externa de servicios, apelando a la colaboración público-privada de manera eficiente y transparente. La herramienta empleada para ello son los bonos de colocación (placemente vouchers, por valor de 2.000 euros) a los que tienen derecho los desempleados con más de seis meses de permanencia en desempleo y pueden utilizarse para contratar los $D$ 
servicios de agencias privadas de empleo (PSA) que solo reciben el pago tras cumplir los objetivos de colocación. Aparentemente, los objetivos alcanzados en este aspecto han quedado muy por debajo de las expectativas y sus resultados son escasamente significativos.

La tercera oleada -Harz IV, con mucho la más problemática- consistió en la reforma del seguro de desempleo. Hasta el 1 de enero de 2005, en que entró en vigor, el sistema alemán de protección contaba con tres piezas: el seguro de desempleo (financiado con una cuota del 3,25 por 100), la «asistencia al desempleo» y la «asistencia social» (estas dos últimas financiadas a través de los presupuestos). El primero proporcionaba ingresos del 60 por 100 del salario neto anterior por un período máximo de 32 meses, dependiendo de la edad y del período cotizado durante los siete años precedentes. De continuar en desempleo, el beneficiario con carencia de medios tenía derecho a la asistencia al desempleo, del 53 por 100 del salario neto (57 por 100, con hijos a cargo) por un período ilimitado. Finalmente, la asistencia social, a cargo de los ayuntamientos, cubre a los que no se cualifican para la anterior, garantizando un ingreso por encima del umbral de pobreza durante un período ilimitado.

La reforma introdujo un primer segmento del seguro de desempleo (prestación de desempleo I, de cuantía igual al seguro anterior) por un período máximo de 12 meses (de 18, para los mayores de 55 años) ${ }^{29}$. Al agotar el cual se pasa a una segunda fase (SD II) cuya prestación no está relacionada con los ingresos anteriores sino que se sitúa al nivel de la asistencia

\footnotetext{
29 En España es el 70 por 100 de la base de cotización durante el primer período de seis meses y del 50 por 100 hasta agotar el derecho, con un máximo de veinticuatro meses para seis años cotizados y con límites de 1.087 euros para un soltero sin hijos y de 1.398 euros para un casado con dos hijos. En el modelo de comparación desarrollado por la OCDE, para el año 2013 el promedio no ponderado (cuatro tipos de familias con dos niveles de ingresos) de la tasa neta de reposición inicial del seguro de desempleo era del 71 por 100 en Alemania y del 69 por 100 en España (70 y 73 por 100 en 2001), situándose la mediana para el conjunto de la OCDE (y para la UE) en el 70 por 100: http://www.oecd.org/els/benefits-and-wages-statistics.htm
}

social, fijando la ley unos objetivos de cobertura de gastos para determinar la cuantía de la prestación en cada caso. Esta última ha sido revisada al alza por la Corte Constitucional y en 2016 se sitúa en 404 euros para un individuo adulto solo, más 364 euros por cónyuge a cargo, 237 euros por hijo menor de 6 años (270 euros entre 6 y 13; 306 entre 14 y 17 y 324 entre 15 y 25; los mayores de 25 años forman una unidad aparte y quienes no están capacitados para trabajar más de tres horas al día, aun conviviendo con beneficiarios del desempleo II, reciben asistencia social) ${ }^{30}$. No existe definición de empleo adecuado para los beneficiarios del D II, salvo que el trabajo ofrecido sea ilegal o el salario se sitúe por debajo del 30 por 100 del fijado por convenio colectivo o por la costumbre de la localidad ${ }^{31}$. La gestión se lleva a cabo mediante 343 consorcios entre la oficina de empleo y el ayuntamiento (mientras que 69 ayuntamientos lo hacen directamente).

Aunque la valoración oficial de la reforma dejaba ver luces y sombras acerca de la concordancia de los resultados alcanzados con los objetivos perseguidos ${ }^{32}$, en lo que existe concordancia es en su eficacia de cara a la contención salarial. Como para dar la razón a las teorías sobre la eficiencia del seguro de desempleo (Acemoglu-Shimer, 1998) y acerca de su impacto sobre el «salario de reserva» (ShimerWerning, 2006) que -sin poner en cuestión su $\triangleright$

\footnotetext{
30 En España actualmente el subsidio de desempleo es de 426 euros durante un periodo máximo de 30 meses (tras agotar la prestación, habiendo cotizado seis años; indefinida a partir de los 52 años), si la renta familiar no supera los 486,5 euros. En el modelo de comparación desarrollado por la OCDE (cuatro tipos de familias con dos niveles de ingresos), en 2014 al término de 60 meses de desempleo la tasa neta de sustitución en Alemania es del 42 por 100 y la de España del 33 pr 100 (28 y 29 por 100 como mediana de la OCDE y la UE), si no se tiene derecho a subsidio de vivienda. Cuando sí se tiene derecho (sin incluir pago de hipotecas), estas últimas cifras se trasforman en: $61,44,52$ y 51 por 100, respectivamente. Antes de la reforma, en 2004 , los niveles se situaban entre 5 y 7 puntos por debajo (eran: 66, 49, 59 y 58 por 100).

31 Para una referencia actualizada de las características del Unemployment Benefit II, y su gestión, véase https://www.arbeits agentur.de/web/content/EN/Benefits/UnemploymentBenefitI/Detail/ index.htm?dfContentld $=$ L6019022DSTBA/485759

32 Véase una síntesis en: http://Www.empleo.gob.es/es/mundo/ Revista/Revista100/61.pdf
} 
existencia-, indagan acerca del nivel óptimo para el funcionamiento fluido del mercado de trabajo, el descenso de este último implícito en la reforma Hartz frenó a partir del momento mismo de su introducción en 2003 la evolución de los salarios efectivos en Alemania, como se observaba en el Gráfico 1 y demuestra el estudio de Kollamn et al. (2014), según el cual el descenso de un punto porcentual en la protección de desempleo se refleja (ceteris paribus) en una caída del 0,3 por 100 del salario real.

Kemmerling y Bruttel (2005) concluyen su trabajo señalando que la reforma Katz del seguro de desempleo significa una ruptura con la lógica tradicional de todo el sistema alemán de seguros bismarckianos, cuyo propósito era garantizar en la medida de lo posible las rentas alcanzadas por el individuo activo en el mercado de trabajo al sobrevenir la contingencia protegida (Espina, 2002). El propósito de la «Asistencia al desempleo II» ya no es mantener las rentas de activo sino proteger del riesgo de pobreza, que es la característica diferenciadora de los sistemas de bienestar inspirados en la doctrina Beveridge, dando con ello la razón a quienes vienen sosteniendo que la separación tradicional entre los «tres mundos de estados de bienestar» se está viendo desbordada por una tendencia generalizada hacia la formación de «estados de bienestar híbridos»33. Según aquellos dos autores la tendencia hacia el deslizamiento entre el modelo Bismarck y el modelo Beveridge afectará en el futuro a otras áreas del estado de bienestar alemán.

\section{Un ensayo general con todo antes de la llegada del euro: la armonización salarial y la fagocitación del empleo de la Alemania del Este}

En paralelo con la estrategia desplegada por los sindicatos alemanes a escala del conjunto

${ }_{33}$ Véase : http://www.theeconomyjournal.com/es/notices/2013/06/ -modernizacion-y-estado-de-bienestar-66805.php de lo que enseguida sería la eurozona, la integración en uno solo de los dos mercados de trabajo de Alemania hizo del propio país, durante los años noventa, un verdadero microcosmos y un laboratorio de lo que sucedería en el conjunto de Europa durante el decenio siguiente. Hacer frente a este reto no precisaba de complejas estructuras de desbordamiento trasnacional de las prácticas internas sino que se encontraba ya en el ADN de la propia DGB: lo que a lo largo del siglo xx se había hecho extendiendo las condiciones de las grandes empresas a las pequeñas, a finales del mismo había que hacerlo extendiendo las condiciones vigentes en el oeste hacia el este de Alemania.

Aunque existan indicios más que suficientes acerca de la ineficiencia de la negociación colectiva de tipo intermedio (Calmfors-Driffill, 1988), no existen estudios específicos sobre el efecto de la extensión de las condiciones de trabajo y empleo desde las grandes a las pequeñas empresas del mismo sector en un territorio determinado, pero sí de los resultados de extender las condiciones establecidas por la negociación colectiva sectorial desde la República Federal de Alemania al conjunto del país después de la reunificación de 1989. Como posteriormente a la desaparición de los grandes conglomerados de la economía estatalizada en Alemania del Este las estructuras empresariales en las dos zonas eran profundamente heterogéneas, los efectos de este proceso resultan equivalentes a aquellos, aunque en este caso las empresas que experimentan el efecto de extensión se encuentren ubicadas solo en una parte del territorio nacional.

Sucede además que contamos con un campo de observación prácticamente completo, ya que el proceso de armonización salarial de las tarifas salariales de convenio puede darse casi por finalizado, como celebraba a finales de 2015 la fundación Boeckler de los sindicatos alemanes al anunciar que tras 25 años de $D$ 
unificación las diferencias entre los salarios pactados en la Alemania del Oeste y en la del Este prácticamente había desaparecido. Quedaría solo un diferencial residual del 3 por 100 , frente a la diferencia del 40 por 100 inicial (aunque en salarios efectivos la diferencia inicial del 42 por 100 se habría reducido solo al 17 por 100$)^{34}$.

Disponemos de un estudio ejemplar (Krueger \& Pischke, 2005) sobre las implicaciones iniciales del tránsito desde el mercado de trabajo de estilo soviético de la Alemania del Este antes de la unificación a la incorporación al mercado de trabajo de la República Federal, convertido en mercado unitario. De hecho, según este estudio las diferencias salariales en el punto de partida eran muy superiores, ya que en 1988 el salario medio en el este equivalía al 31 por 100 del salario del oeste (con una diferencia del 70 por 100), de modo que el diferencial adoptado por la DGB como punto de partida, referido a 1991, incorporaba ya los efectos de la conversión de los dos marcos a un tipo de paridad de uno por uno, que debió de significar casi una duplicación, ya que todos los indicadores señalaban que el tipo de cambio de paridad era de uno por dos. Bien es verdad que, al agregarse el efecto fiscal y de bienestar el ingreso medio familiar de Alemania Oriental equivalía al 55 por 100 del de la RFA, con una diferencia entre ellos del 45 por $100^{35}$.

Tan solo la conversión de los dos marcos a tipo de cambio uno por uno provocó un desequilibrio de costes laborales unitarios relativos (tomando en cuenta los diferenciales de productividad) del orden del 50 por 100 , lo que no pudo dejar de provocar un cierre masivo de empresas en el este, con el correspondiente colapso del empleo. Es este último el que produjo un colosal aumento de la productividad

\footnotetext{
34 Véase East-West wage gap vanishes at collective bargaining level, September 24, 2015 http://www.boeckler.de/impuls_2015_ 14_1.pdf

35 Krueger \& Pischke (2005), Tabla 12.1.
}

que consiguió ecualizar los CLU de las dos zonas en coincidencia con la llegada del euro ${ }^{36}$. Lo más grueso de la ecualización de salarios la habían realizado la conversión del marco y los primeros años de la extensión hacia el este de las estructuras de determinación de salarios del oeste, como observaron Krueger \& Pischke, ya que los diferenciales de salarios negociados se situaron en el 16 por 100 en 1994 y en el 9 por 100 en 1998 (y los efectivos en 23 y 20 por 100 respectivamente) $)^{37}$.

Según la doctrina de la DGB el propósito de la estrategia de ecualización salarial consiste en provocar una elevación de la productividad en las empresas menos eficientes. Si la brusca caída de los CLU orientales ${ }^{38}$, registrada durante el decenio que siguió a la unificación, se debiera al cumplimiento de ese objetivo tal cosa habría requerido al menos la duplicación de la productividad de las empresas de esa zona, que en el momento de la unificación se situaba en torno al 35 por 100 de la de las empresas de la antigua RFA (Blien et al., 2016/183). Por el contrario, tras la colosal revaluación del marco oriental lo que ocurrió fue una brutal «deflación interna», a través de una profunda depresión que hizo caer la producción industrial a la mitad en tan solo dos años y el empleo en un 23 por 100 (además de colocarse al 18 por 100 de los empleados en régimen de trabajo a tiempo parcial, complementando sus ingresos el Estado, y realizarse una contratación masiva en trabajos públicos). En el decenio subsiguiente la tasa de desempleo llegaría a duplicarse, situándose en 2005 por encima del 20 por 100 (Gráfico 4). Esta dinámica se vio acompañada por una agresiva campaña de afiliación por parte de la DGB y por dos campañas de negociación colectiva que establecieron el objetivo de cumplimiento de equiparación salarial para 1994 o 1995, tras $\triangleright$

\footnotetext{
${ }^{36}$ Sobre esta extraña forma de convergencia ironizaba The Economist el 7 de noviembre de 2014 en Kommen together. http://www.eco nomist.com/blogs/graphicdetail/2014/11/daily-chart-3

37 Datos de la fundación Boeckler.

38 Incluyendo todo Berlin Occidental en el Este, los CLU de las manufacturas orientales pasaron de suponer el 160 por 100 de las del Oeste, al 111 por 100 entre 1991 y 1999 (Gerling, 2002/47), Tabla 14.
} 
GRÁFICO 4

TASA DE DESEMPLEO EN RELACIÓN CON LA POBLACIÓN ACTIVA DEPENDIENTE (\%)

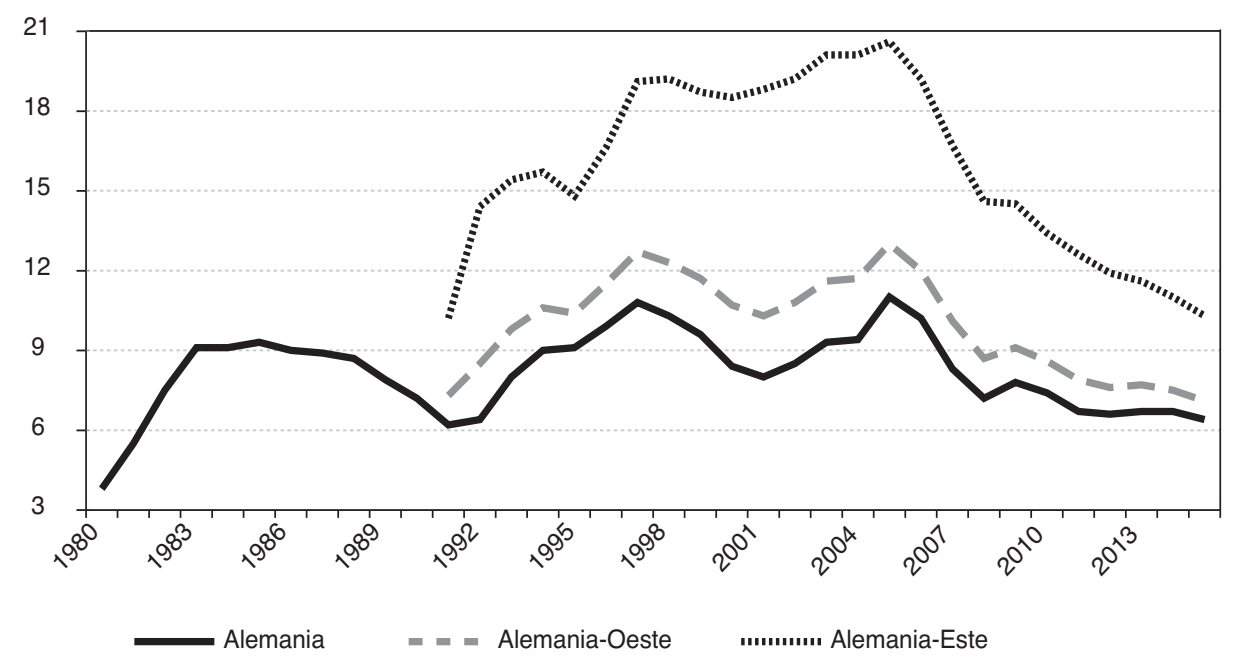

Fuente: http://www.bpb.de/nachschlagen/zahlen-und-fakten/soziale-situation-in-deutschland/61718/arbeitslose-und-arbeitslosenquote

producir una elevación del 39 por 100 en los salarios nominales durante el trienio 1988-199139.

El propósito de IG Metall consistía en evitar la permanencia de un desequilibrio que todavía en 1991 situaba el salario del metalúrgico de Sajonia en el 45 por 100 del metalúrgico bávaro, con la consiguiente amenaza de deslocalización. Akerloff y su equipo observaron también que los directores de las empresas situadas en la Treuhand (la agencia de privatización o banco malo de la época) apenas cerraron empresas y prácticamente no se resistieron a las exigencias salariales de los sindicatos. Lo más significativo de todo el proceso es que ya en 1991 los alemanes orientales que se desplazaban a diario para trabajar en el oeste ganaban aproximadamente un 83 por 100 más de lo que ganaban los que se quedaban en el este (sin que sus características personales explicasen esa diferencia) y solo el

39 El proceso de rápida equiparación salarial lo estudiaron Krueger \& Pischke (2005, p. 408 y ss.). Por lo que se refiere a la distribución de los crecimientos salariales por decilas en el trienio 1988, el crecimiento de la decila superior duplicó al de la inferior, introduciendo mayores niveles de desigualdad para primar los años de escolarización, especialmente técnica y universitaria, el trabajo administrativo y profesional, el autoempleo y el empleo en el sector privado, en los que la competencia para los trabajadores cualificados del oeste podía ser más fuerte (p. 403). Véase también Bonesmo (2012, Tabla 3).
15 por 100 menos que los del oeste en los mismos trabajos y con mucha menor experiencia, lo que suponía un poderoso factor de atracción, que suele ser la causa determinante de las migraciones (King, 2012). Por su parte, la probabilidad de desempleo en la Alemania del Este para personas sin formación postsecundaria era del 33 por 100, aproximadamente el triple que en el oeste, proporcionando un factor adicional de «expulsión», que venía a completar un modelo migratorio completo con las dos fuerzas (pull-push) actuando en dirección complementaria.

Obviamente, el propósito de la estrategia de equiparación salarial este-oeste aplicada por la DGB iba dirigida a evitar la competencia entre las dos Alemanias y la deslocalización industrial entre ellas (aunque la victoria en este terreno sería pírrica, puesto que la deslocalización se produciría enseguida hacia los países de la ampliación), pero se pretendió explicar como una medida dirigida a forzar la elevación de la productividad en la zona oriental para equipararla con la del resto. Hoy resulta evidente que en este aspecto la estrategia del «látigo salarial» fracasó, pues ocurrió precisamente lo contrario, como demostró Lehmann (2003) a partir de la encuesta realizada por el Instituto Halle (IWH) $\triangleright$ 
a una muestra de empresas manufactureras de Alemania Oriental: no existió relación entre el aumento de tarifas salariales y el aumento de la productividad desfasado en un intervalo de tiempo, sino más bien lo contrario, la relación entre las dos variables fue negativa, especialmente en las empresas que habían experimentado fuertes crecimientos de sus CLU en el pasado inmediato.

En general, existe también evidencia concluyente acerca de que en lo relativo al aumento de la productividad y la competitividad solo aparecen resultados efectivos cuando la acción colectiva de los consejos de empresa y el ejercicio de la autonomía colectiva se lleva a cabo mediante acuerdos celebrados a ese mismo nivel, y solo para las empresas con más de cien trabajadores. El análisis de Müller \& Stegmaier (2015) -que emplea técnicas de panel y utiliza la base de datos construida por la Agencia Federal de Empleo (IBA) desde 1993-40 establece que durante los primeros cinco años a partir de su implantación en la empresa los comités (work councils) producen sistemáticamente una disminución de la productividad. A partir de entonces se detectan también efectos negativos en el corto plazo y «pautas nocivas en el largo plazo» para las denominadas «pequeñas empresas», definidas como aquellas que tienen menos de cien trabajadores, excluyendo a las de menos de cinco. Solo las empresas de tamaño superior consiguen a partir del quinto año mejoras directamente imputables a la interacción entre los consejos de los trabajadores y la dirección de la empresa. Esto es, el estudio confirma las profundas diferencias en el comportamiento de las empresas según tamaño, y se ve obligado a excluir a las de Alemania del Este «porque el aprendizaje de los comités de empresa debe ser diferente en una economía en transición, al disponer de una

\footnotetext{
40 Desde 1996 en el este, aunque el estudio se refiere solo a la Alemania Occidental para el período 1998-2012 y para el censo de empresas con más de cinco trabajadores.
}

tradición distinta en materia de resolución de conflictos y de participación de los trabajadores" (lo que viene a reconocer implícitamente el fracaso de la estrategia uniformista seguida por el sistema alemán de relaciones industriales desde la unificación).

Quien hizo una autopsia más contundente de la fracasada política de «látigo salarial» tras la reunificación fue Hans-Werner Sinn (2007, p. 155). En sus propias palabras:

«La unión monetaria alemana elevó los costes salariales [del este] a niveles equiparables a los de Portugal, pero con las subsiguientes elevaciones los costes sobrepasaron a los de Irlanda en 1992, a los de Italia en 1995 y a los de Francia en 1996... Eso es lo que explica que los inversores internacionales no acudieran a las privatizaciones de la Treuhand... [al contrario] el boom inversionista que debiera haber producido un crecimiento salarial inducido por la demanda (demand-driven) nunca tuvo lugar. Es más, la inversión per cápita en el este cayó incluso por debajo de la del oeste a partir de 2000. Ese es el precio de que los crecimientos salariales se anticipen al crecimiento de la productividad, en lugar de ocurrir lo contrario»41.

Del análisis de aquella experiencia, Sinn extrajo las siguientes conclusiones:

- El principio a igual trabajo igual salario solo puede aplicarse cuando las condiciones son idénticas... Aunque la fuerza de trabajo estuviera bien capacitada en el este, carecía de muchas capacidades (comerciales, legales, etcétera) que la hacían menos rentable. Estas capacidades solo se adquieren tras una larga experiencia en la economía abierta y de mercado competitivo. En eso consiste el proceso de convergencia, pero consume tiempo.

- Eso mismo cabe afirmar del establecimiento de redes de negocios, infraestructuras y espíritu empresarial. La tupida red de familias $\triangleright$

\footnotetext{
41 Un proceso muy parecido se había registrado en España durante los años setenta: CD 102.2, 12 de septiembre de 2014: http://ima genesbibliotecacentral.minhap.gob.es/pdfpublicaciones/Literaturagri s/cd102-2_2014.pdf
} 
emprendedoras con alto grado de conocimiento empresarial heredado y trasmitido, que es el esqueleto de la economía de la Alemania del Oeste (enriquecida con la huida de emprendedores desde el este mucho antes de la unificación) constituye precisamente el brazo motor de la elevada productividad del trabajo en la antigua RFA, en ausencia de la cual la elevación de salarios inducida en el este resultó insostenible y produjo una rápida destrucción del tejido industrial preexistente, bloqueando la llegada de nueva inversión. El otro leit motiv en que se sustentó la equiparación salarial fue evitar que las fuertes diferencias salariales produjesen una emigración masiva desde el este hacia el oeste... Cualquier estimación razonable indicaba que el proceso de convergencia para crear suficientes empleos productivos en el este duraría más de dos decenios, pero la imposición de un calendario de equiparación apremiante convirtió el objetivo en algo irrealizable.

- Además, al complementarse la medida salarial con fuertes subsidios a la inmovilidad (y a la permanencia en desempleo), se creó la ilusión de que el empleo de alta remuneración acabaría llegando al este. De los 3,6 millones de trabajadores que perdieron su empleo en la antigua RDA, 2,2 no buscaron empleo en el oeste, mientras que la fuerte demanda de trabajo atraía hacia la antigua RFA entre 1990 y 2004 a más de 2,7 millones de trabajadores inmigrantes de fuera de Alemania.

- En realidad, aunque la política de equiparación salarial se realizara formalmente adoptando objetivos de equidad «las decisiones no las adoptaban aquellos cuyos intereses se encontraban en juego, sino los empleadores y las organizaciones de trabajadores que representaban a los competidores occidentales de las empresas de la Alemania del Este. Tampoco nadie deseaba que la antigua RDA fuera una localización atractiva para los inversores extranjeros. No querían a los japoneses en el patio de atrás de su casa, empleando a mano de obra competente, conocedora de la lengua y perfectamente integrada en el país».

- No obstante, haciendo uso de la legislación alemana sobre negociación colectiva (Zachert, 2004), los empresarios de Alemania Oriental abandonaron masivamente las estructuras representativas y dejaron de estar vinculados a los convenios sectoriales: en 2001 el 78 por 100 de las empresas (aunque solo el 55 por 100 de los trabajadores de esa zona) no estaban cubiertos por convenio colectivo alguno ni eran en conjunto elegibles para la extensión de los mismos (para lo que al menos un 50 por 100 del empleo debe encontrarse ya acogido al mismo). Pero ya era demasiado tarde, el proceso de equiparación se encontraba muy avanzado y era difícilmente reversible, mientras el desempleo seguía creciendo hasta el 20 por 100 en 2005, duplicando al de la zona occidental. Por mucho que tras la depuración de empresas y empleo los CLU del este fueran ya competitivos, el país había dejado de ser atractivo para los inversores y se desangraba con la emigración.

Esta evidencia se fue imponiendo paulatinamente, hasta el punto de que ha existido una correspondencia casi absoluta entre las tasas de desemple $\mathrm{O}^{42}$ y las tasas de emigración de los diferentes Länder ${ }^{43}$ : en conjunto, entre 1989 y 2013 la zona oriental perdió casi un 15 por 100 de su población, mientras que la occidental ganó más del 4 por 100. Las zonas más castigadas del este perdieron hasta el 30 por 100 de efectivos, mientras que las más favorecidas del oeste ganaban un 20 por 100 . Hasta 2030 se prevé que Alemania del Este pierda otro 7,8 por 100 de su población activa ${ }^{44}$.

42 Véase la distribución actual en: http://www.empleo.gob.es/ es/mundo/Revista/Revista201/68.pdf y la situación por Länder en 2007, en: http://www.empleo.gob.es/es/mundo/Revista/Revista103/ 74.pdf

${ }^{43}$ Los mejores gráficos están en: http://www.economist.com/ blogs/graphicdetail/ 2014/11/daily-chart-3. Los mapas sobre desigualdad, en: http://library.fes.de/pdf-files/wiso/12390.pdf

44 Frente a un descenso medio del 2 por 100: http://www.empleo. gob.es/es/mundo/Revista/Revista192/60.pdf 
Puede considerarse que lo ocurrido en Alemania del Este constituye un vaticinio que anticipaba lo que podría ocurrir de no llevarse a cabo la construcción de la UEM con sumo cuidado, como anunciaron en su momento Akerloff et al. (1991).

\section{La pérdida de vigencia de la negociación colectiva erga omnes en Alemania y la crisis de la eurozona}

Ciertamente, la buena coyuntura del empleo experimentada por la antigua Alemania Occidental tras la crisis de la eurozona (que le permitió cosechar también los resultados de la estrategia salarial de renunciar a las ganancias de competitividad practicada desde la llegada del euro $)^{45}$ hace que en esta última etapa la sangría de empleos de Alemania Oriental encuentre buena acogida en el oeste -particularmente en el sur, que vuelve a encontrarse en situación de pleno empleo y hambre de brazos- y que el desempleo se reduzca también allí sustancialmente, hasta situarse por debajo del 9 por 100 (frente al 5,8 por 100 en la antigua RFA ${ }^{46}$, pero el fracaso económico y del empleo experimentado por la antigua Alemania Oriental, tras 25 años de unificación, ha terminado por destruir el sistema de extensión de los convenios colectivos responsable de todo este proceso (mucho más en el este que en el oeste, aunque también aquí): en el año 2013 mientras el 52 por 100 de los empleos se encontraban cubiertos por la negociación colectiva en el oeste (el 48 por 100 en el sector privado, mayoritariamente con acuerdos de industria, generalmente de alcance regional) en la Alemania del Este la cobertura total era del 35

\footnotetext{
45 Lo que contribuyó a desencadenar y a agravar la crisis de la eurozona (Bofinger, 2015).

46 Aunque bajo la definición de desempleo de la OIT la tasa media de desempleo alemana fuera ya en noviembre 2015 del 4,6 por 100: http://www.empleo.gob.es/es/mundo/Revista/Revista197/49.pdf
}

por 100 (28 por 100 en el sector privado) y, lo más significativo de todo, solo la tercera parte de ellos tenía acuerdos de industria, lo que se debe al abandono masivo de la afiliación a las organizaciones patronales por parte de los empresarios. En síntesis, en 2014 de los 70.000 convenios negociados en toda Alemania solo 500 (un 0,7 por 100) llegaron a tener eficacia general a través de procedimientos de extensión ${ }^{47}$.

Ya desde finales de los noventa, la erosión en el alcance de la negociación a escala de industria regional dio lugar a modificaciones legales que permiten al ministro de Trabajo fijar salarios mínimos sectoriales en áreas no cubiertas por la negociación ( $\mathrm{y}$, por tanto, sin el requisito del 50 por 100), pero se trata de medidas excepcionales que se han empleado sobre todo en sectores y profesiones en los que empresas no alemanas pagan bajos salarios a personas de su propio país (bajo el síndrome del «fontanero polaco»). En cambio, el Gobierno de coalición formado tras las últimas elecciones acordó establecer por primera vez un salario mínimo legal de 8,5 euros por hora para todo el país. La ley fue adoptada el 3 de julio de 2014, para entrar en vigor con una serie de excepciones en 2015 y con alcance general el 1 de enero de $2017^{48}$. La OCDE estimó que cuando la medida fue aprobada un 11,4 por 100 de los trabajadores alemanes no alcanzaba ese mínimo y que su aplicación en aquel momento hubiera supuesto una elevación media del 1,2 por 100 en la masa salarial total ${ }^{49}$.

Dado el retraso salarial acumulado por el país desde la llegada del euro (que las IFI y la OCDE consideran desleal), esa elevación podría haber quedado absorbida, en promedio, $D$

\footnotetext{
47 http://www.worker-participation.eu/National-IndustrialRelations/Countries/Germany/Collective-Bargaining

48 Véase Actualidad Internacional Sociolaboral n 182 (septiembre 2014), página 95 http://www.empleo.gob.es/es/mundo/Revista/ Revista182/95.pdf

49 OECD (2015, pág 36, Tabla 1.1).
} 
por las revisiones salariales del año $2015^{50}$, y con mayor motivo en las múltiples excepciones que permitirán aplicar la medida hasta 2017, tras tres revisiones salariales anuales ${ }^{51}$. Bien es verdad que el impacto será muy desigual entre las dos Alemanias (con un 20 por 100 de trabajadores por debajo del mínimo en el este, lo que, de aplicarse la ley inmediatamente supondría un 2,6 por 100 de elevación), y entre las empresas con más y con menos de 20 trabajadores (con un 22 por 100 de trabajadores por debajo del mínimo en las de menos de 20 trabajadores, lo que supondría un 3 por 100 de aumento medio, que se distribuirá también en dos anualidades). De modo que lo que antes venía realizándose a través de la extensión de la negociación colectiva ahora se hará en parte a través de la ley de salario mínimo (titulada, paradójicamente «de fortalecimiento de la autonomía colectiva»).

Esto es, en Alemania -cuna de la negociación colectiva sectorial dual- el sistema quedó prácticamente destruido por su utilización abusiva tras la unificación, al ser empleado para evitar pretendidamente el dumping social derivado del colapso del empleo en la zona oriental, lo que bloqueó su crecimiento. Como señala Boeri $(2009,2014,2015)$, este sistema está viciado y el grado de armonización salarial que se considere deseable debería realizarse en todas partes a través de la legislación de salario mínimo. En Alemania, eso se hará ahora en un contexto económico próximo al pleno empleo, que provoca ya fuerte presión inmigratoria y los efectos de una legislación de este tipo pueden dosificarse razonablemente para que no dañen al empleo, como señala Schmitt

50 Véase el convenio colectivo del metal para la Alemania del Noroeste, suscrito el junio de 2014 en: http://netkey40.igmetall.de/ homepages/eu_projekt_pl/hochgeladenedateien/2014_07_17_Steel -agreement.pdf. Para 2016 el crecimiento medio es de 2,3 por 100: https://www.igmetall.de/pressemitteilungen-2015-17996.htm

${ }^{51}$ La revisión salarial media en la industria del metal a lo largo de 2015 para el conjunto de Alemania (3,7 millones de empleados) fue del 3,4 por 100. El recién elegido dirigente de IG Metall, Joerg Hofmann, prometió endurecer posiciones en 2016: http://www.reuters.com/arti cle/germany-wages-unions-idUSL8N15429I
(2013), pero en otros casos no ocurre así, ni ocurrirá en un horizonte previsible, por lo que resulta imprescindible corregir la «perversión» uniformista de los sistemas de negociación colectiva, especialmente en los países que presentan tasas de empleo/población más bajas que la media de la EA y tasas más elevadas de desempleo ${ }^{52}$.

Todos los indicadores arrojan el balance de que adoptar esta estrategia y diseminar la estrategia contrapuesta en los países del sur resultó exitosa para Alemania, aunque el éxito no se debiera exclusivamente al efecto de contagio y de desbordamiento impulsado desde ese país, sino que se vio favorecido por la fiebre consumista y reivindicativa asociada a las burbujas de crédito que experimentó la economía internacional durante la «era Greenspan» y a su fácil transmisión dentro de la nueva eurozona (Espina, 2010), especialmente en aquellos países con negociación colectiva dual que siguieron la orientación impartida por la DGB a través de la CES y no adoptaron una estrategia explícita y firme de contención salarial -como hicieron Alemania y el Benelux, y también los países nórdicos, siguiendo su propia dinámica secular de cooperación, (Calmfors, 2013) - ${ }^{53}$, lo que profundizó la crisis ulterior, ratificando la evidencia según la cual lo que diferencia a las expansiones financieras buenas de las malas (y la profundidad de la recesión ulterior) es el juego de salarios, productividad y costes laborales unitarios (Gorton y Ordóñez, 2016), que son presa fácil para trasmitir la euforia.

En España, al amparo de una regulación ineficiente de la negociación colectiva los fenómenos de contagio desde los sectores con burbuja, a salvo de la concurrencia internacional (y con crecimientos negativos de la productividad), se trasladaron fácilmente hacia las manufacturas del sector descubierto y los servicios, arrastrando $D$

52 En los gráficos de OECD (2015. pp. 24 y 25) los primeros son Grecia, Italia, España, Turquía Francia, Hungría y Polonia. Los segundos Grecia, España, Portugal, Italia y Eslovaquia.

53 Como se estudió en el Cuaderno de Documentación CD 102.2, ya citado. 

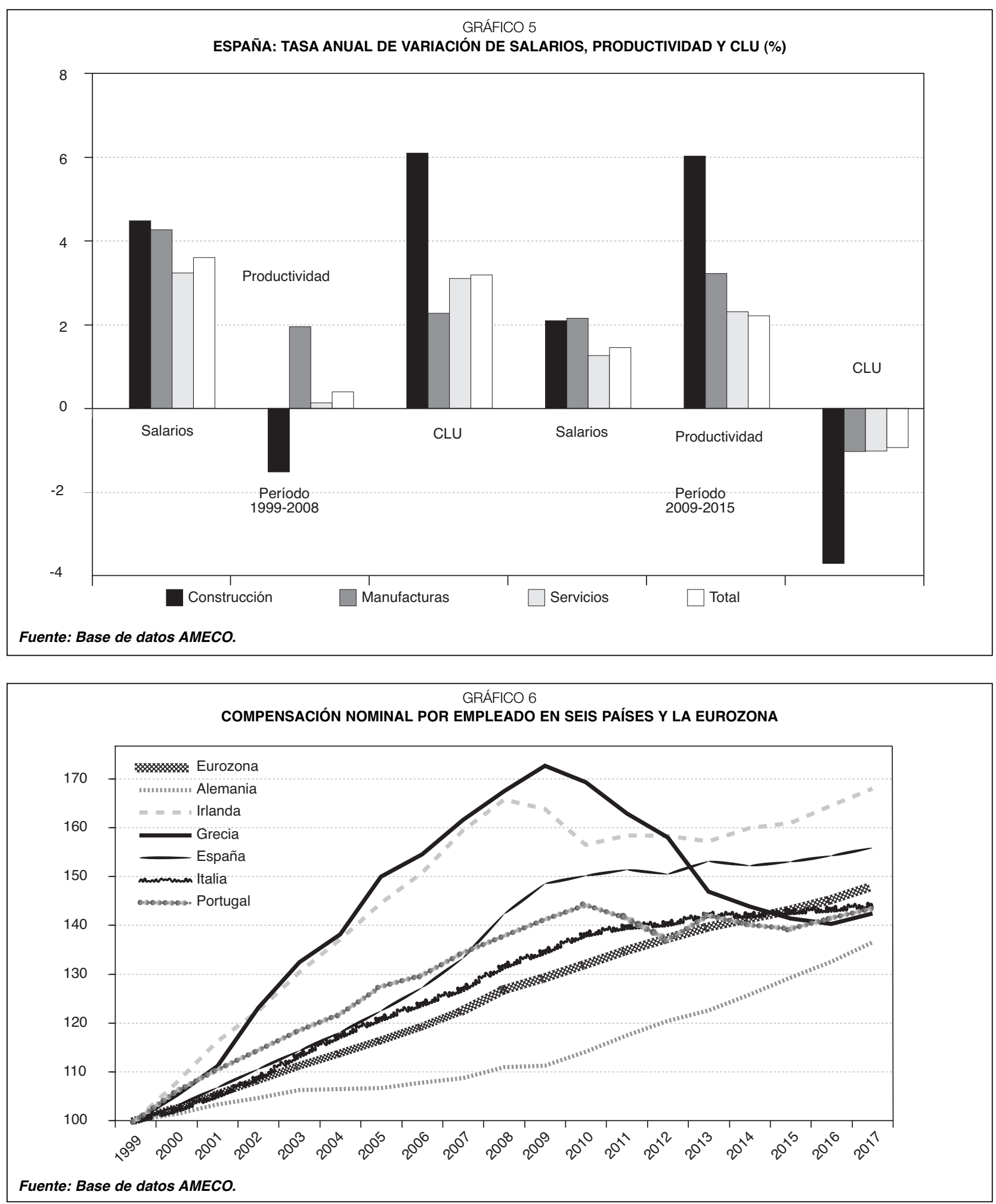

al conjunto, como se observa en el Gráfico 5, algo que no ocurrió en el conjunto de la eurozona (Cuadro 1), pero fue pauta común en toda la periferia (Gráficos 6 y 7).
Las conclusiones de Boeri resultan contundentes y coinciden con la corriente principal de análisis de los resultados de los distintos modelos de negociación colectiva. 


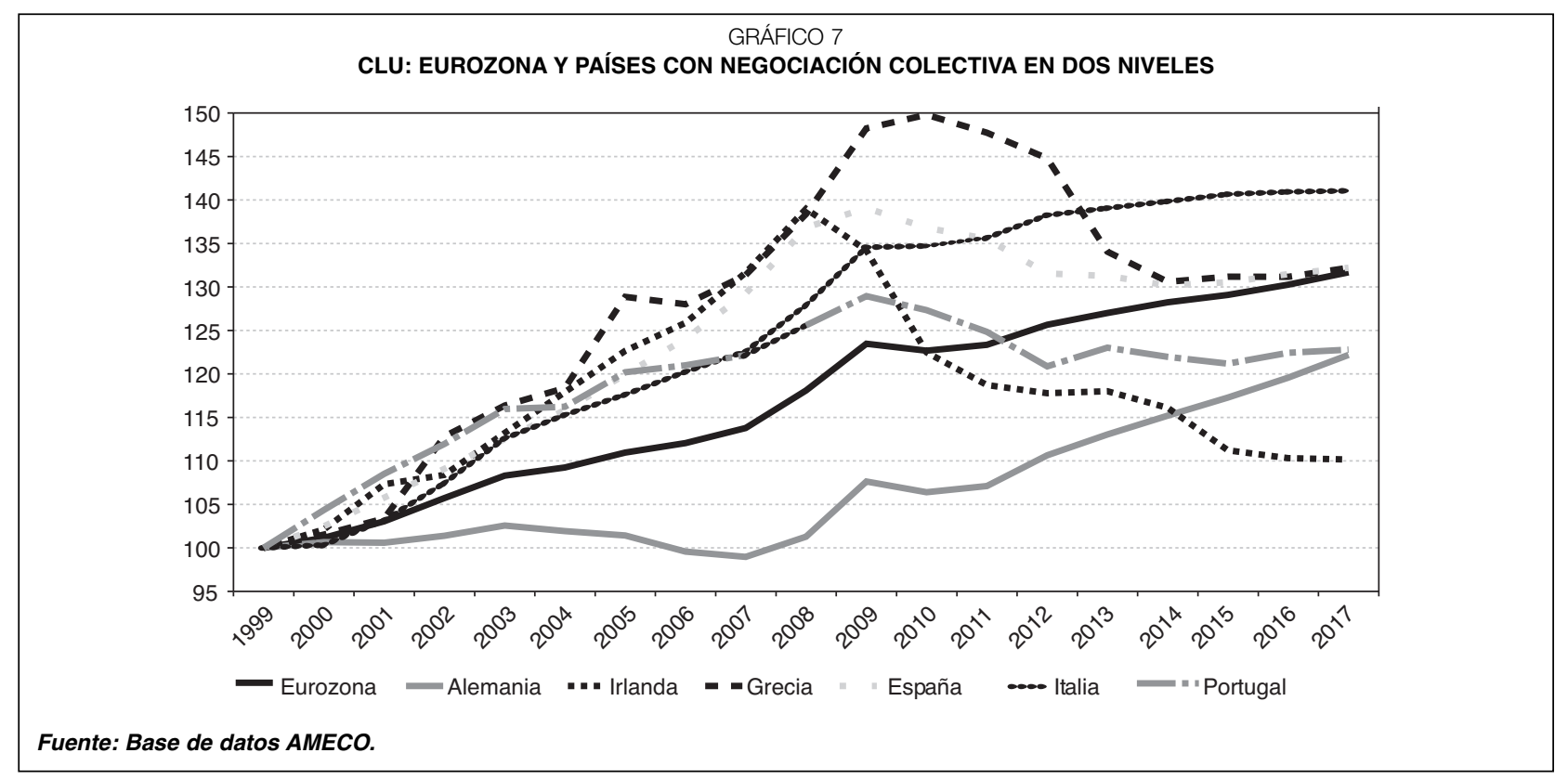

\begin{tabular}{|c|c|c|c|c|c|c|}
\hline \multirow[b]{3}{*}{ Sectores } & \multicolumn{5}{|c|}{$\begin{array}{l}\text { CUADRO } 1 \\
\text { EUROZONA-12. TASA ANUAL DE VARIACIÓN DE SALARIOS, PRODUCTIVIDAD Y CLU (\%) }\end{array}$} & \\
\hline & \multicolumn{3}{|c|}{ Período 1999-2008 } & \multicolumn{3}{|c|}{ Período 2009-2014 } \\
\hline & Rem./empl. & PIB/Empl. & CLU & Rem./empl. & PIB/Empl. & CLU \\
\hline Construcción ........... & 2,5 & $-0,3$ & 2,8 & 3,9 & 0,3 & 3,6 \\
\hline Manufacturas ......... & 2,6 & 2,5 & 0,1 & 3,6 & 2,3 & 1,3 \\
\hline Servicios....................... & 2,3 & 0,4 & 1,8 & 2,5 & 0,3 & 2,2 \\
\hline Total ........................... & 2,3 & 0,8 & 1,6 & 2,7 & 0,6 & 2,1 \\
\hline \multicolumn{7}{|c|}{ Fuente: Series AMECO. } \\
\hline
\end{tabular}

- «Las estructuras duales de negociación, que hacen prevalecer los niveles mínimos establecidos por la negociación sectorial sobre los establecidos por la negociación en el ámbito de la empresa, tienden a combinar la rigidez salarial de los sistemas centralizados con la ausencia de cualquier consideración hacia las restricciones macroeconómicas que sí se observa en los sistemas totalmente descentralizados".

- Para reconciliar flexibilidad microeconómica con estabilidad macroeconómica hay que desdoblar los sistemas duales en dos verdaderos ramales (uno con negociación a escala de empresas individuales y otro centralizado, para las empresas que no participan en el primero). Además, los acuerdos supraempresariales deberían establecer exclusivamente reglas y no niveles salariales aplicables de manera uniforme a todas las empresas (independientemente de su productividad y resultados). Los suelos salariales no deberían establecerse mediante negociación colectiva centralizada sino solo a través de leyes que fijen el salario mínimo (situado a un nivel que no implique efectos fuertemente negativos sobre el empleo)».

- «En suma, el diseño preferible para la negociación colectiva consiste en un estructura en la que la negociación a escala de planta, cuando exista, prevalezca sobre la negociación a cualquier otro nivel y donde la negociación sectorial o nacional tenga tan solo valor subsidiario, aplicándose a las empresas que no dispongan de convenio colectivo propio".

Las implicaciones de todo ello sobre el crecimiento y el empleo de los países dista mucho de encontrarse bien estudiada. Quizás la más grave consista en que, al reducir extraordinariamente el grado de concurrencia interior (forzando $\triangleright$ 
8.A. REMUNERACIÓN NOMINAL POR EMPLEADO: TASAS ANUALES DE VARIACIÓN (\%)

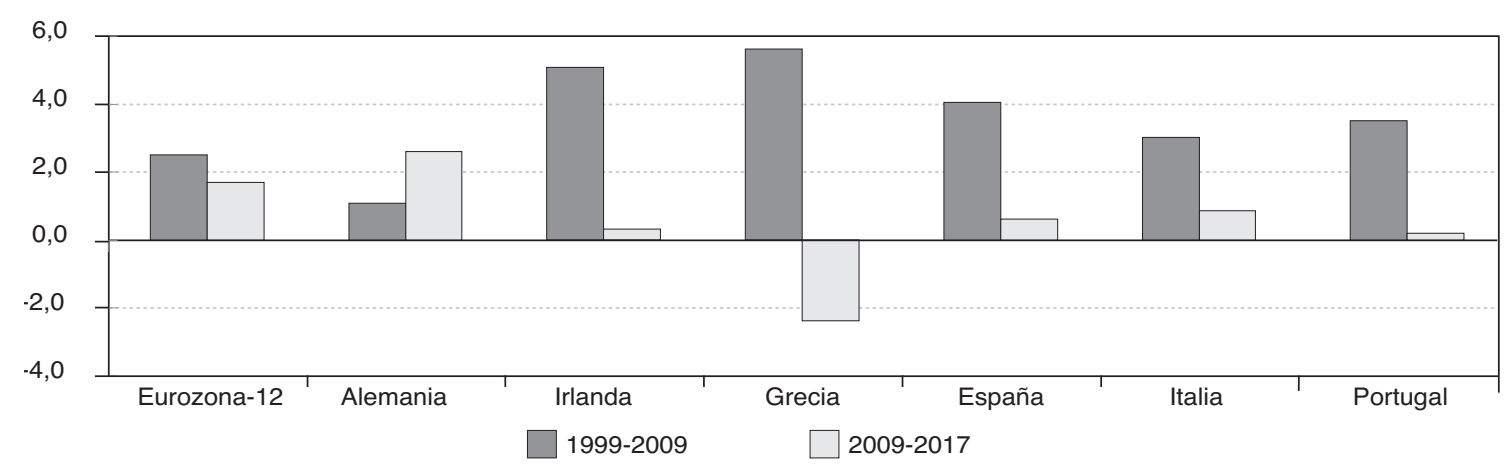

8.B. PIB POR EMPLEADO: TASAS ANUALES DE VARIACIÓN (\%)

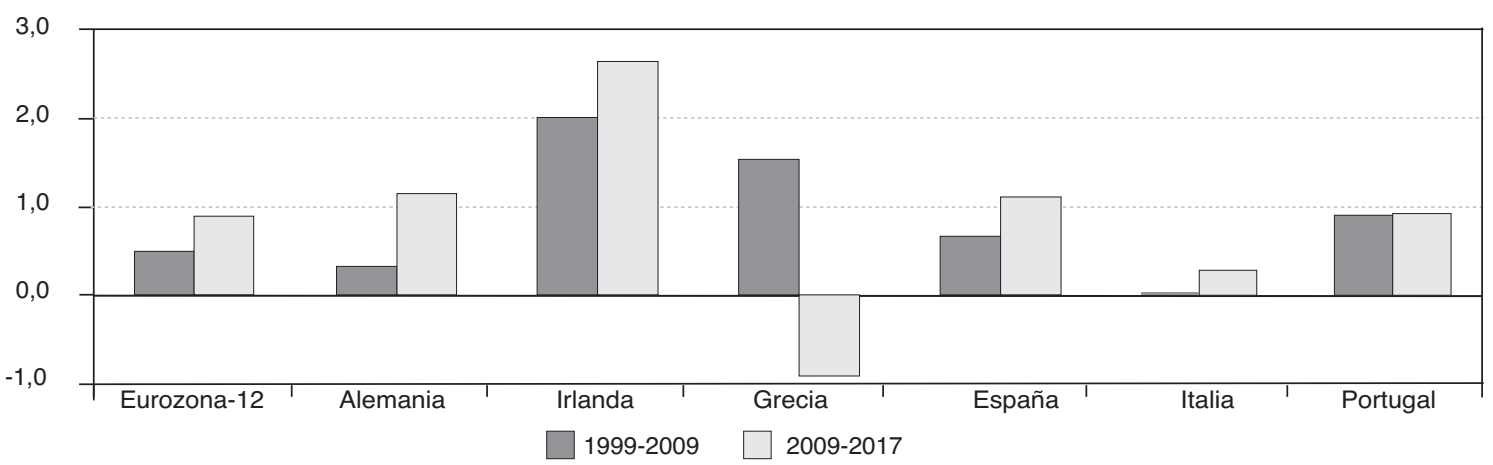

8.C. COSTES LABORALES UNITARIOS (CLU): TASAS ANUALES DE VARIACIÓN (\%)

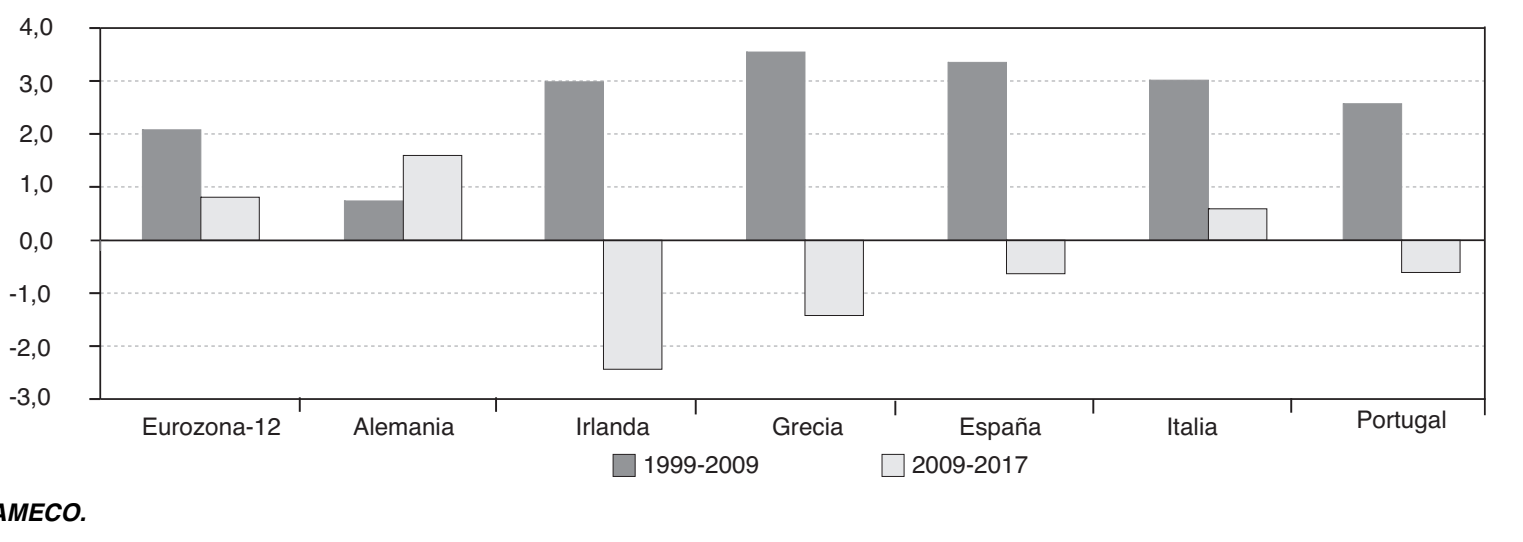

el crecimiento de los costes de las pymes, lo que eleva la relación precio/coste marginal para las empresas más grandes y eficientes) desaparece el principal impulso para la innovación y la mejora de la productividad, de acuerdo con el modelo schumpeteriano de crecimiento construido por Aghion, Akcigit y Howitt (2016), ya que el modelo de negociación colectiva dual funciona como la principal herramienta para reducir el grado de competencia, utilizando la tendencia observada hacia una mayor desigualdad de remuneraciones entre empresas para convertir en inviables a las menos capaces de seguirla (Song et al., 2015). De esta forma se ciegan las asimetrías inherentes al crecimiento, frenándolo y reduciendo el empleo (Acemoglu et al., 2016). La síntesis representada en los Gráficos 8.A, 8.B y 8.C indica que los costes laborales unitarios de estos países crecieron entre 1999 y 2009 a una tasa de $D$ 
variación anual un punto porcentual por encima de los de la eurozona y de los países centrales (y más de 2,5 puntos por encima de los de Alemania) de modo que si el ajuste de los países centrales después de la crisis ya fue considerable, el de los países periféricos (excepto Italia, que sigue pendiente de realizarlo) obligó a crecimientos constantemente negativos de los CLU, apelando generalmente a la contención salarial (más intensa en Grecia) y, sobre todo, mediante reducciones drásticas del empleo para mejorar la productividad (aunque en Grecia la violenta contracción de producto fue todavía superior, reduciendo la productividad, signo de que la estrategia aplicada, antes y después de la crisis, resultó desastrosa).

\section{Conclusión}

La experiencia de lo que estaba ocurriendo en la Alemania Oriental después de la unificación debería haber alertado acerca de los riesgos que se corrían en los países periféricos, al mantener sistemas de negociación colectiva que propician el contagio salarial a través de la uniformidad retributiva y de condiciones de trabajo practicada por los convenios colectivos de rama. Además, en Alemania la pretensión de aplicar esa forma anómala de negociación ha terminado por bloquear los procedimientos de extensión de convenios, hasta el punto de que la eficacia general de los salarios mínimos ha habido que realizarla por ley, algo a lo que la tradición alemana secular de relaciones industriales era por completo ajena. A ello ha contribuido la observación de la evidencia, cada vez más común, de que salarios mínimos en torno al 40 por 100 del salario medio de los países (que es la situación típica dentro de la OCDE) no son nocivos para el empleo, como se observa en la escasa correspondencia entre tasas de ocupación y nivel relativo del salario mínimo ${ }^{54}$.

\footnotetext{
54 Véase OCDE (2015, pp. 24-37)
}

Resulta inevitable, por tanto, concluir como lo hace Tito Boeri (2014):

«Es imprescindible reformar el sistema de relaciones industriales para descentralizar la negociación de los salarios, de modo que los acuerdos a nivel de rama solo resulten efectivos para aquellas empresas, principalmente pequeñas, en las que no tiene lugar la negociación colectiva a escala de establecimiento".

«Los acuerdos colectivos supraempresariales solo deberían establecer reglas salariales relativas, pero sin aplicar niveles o variaciones salariales de manera uniforme para todas las empresas, sin relación alguna con sus resultados específicos».

En buena medida este impacto diferencial del sistema dual de negociación colectiva sobre los distintos grupos de empresas clasificadas según su tamaño es responsable de la ineficiencia macroeconómica que viene imputándose a esta modalidad de determinación de los salarios desde el estudio pionero de Calmfors-Drifill (1988) $)^{55}$, en el que formularon una hipótesis que se mantenía incólume antes de la crisis actual (Driffill, 2005), aunque ya se observase dentro de Alemania un repliegue de sus efectos, al amparo de la legislación vigente en ese país (Zachert, 2004), que obliga a que los negociadores sindicales presentes directamente en la mesa de negociación (y los empresarios afiliados efectivamente a la organización negociadora) representen, al menos, al 50 por 100 de los empleos y de las empresas de la correspondiente rama, para que pueda plantearse un expediente de extensión del convenio a todo el ámbito al que va dirigido, dinámica esta que ha quedado prácticamente abandonada desde la aparición del euro.

55 Véase también Cuaderno de Documentación 102.2 (12-IX, 2014), $\S 4.1$, ya citado. 


\section{Bibliografía}

[1] ACEMOGLU, D. y SHIMER, R. (1998). «Efficient Unemployment Insurance». NBER Working Paper $\mathrm{n}^{\circ}$. 6686, agosto. Disponible en: http://www.nber.org/papers/w6686.pdf

[2] ACEMOGLU, D. ; GEORGY, E. y KONSTANTIN, S. (2016). «Social Mobility and Stability of Democracy: Re-Evaluating De Tocqueville». NBER Working Paper $\mathrm{n}^{\circ}$ 22174, abril. Disponible en: http://www.nber.org/papers/w22174

[3] ACTU (Australian Council of Trade Unions) (2015). ACTU Submission to the Productivity Commission's inquiry into the workplace relations framework. Disponible en:

http://www.actu.org.au/our-work/submis sions/actu-submission-to-the-productivitycommission-inquiry-into-the-workplace-rela tions-framework-march-2015

[4] AGHION, P.; AKCIGIT, U. y HOWITT, P. (2016). "What Do We Learn from Schumpeterian Growth Theory?». NBER Working Paper, $\mathrm{n}^{\circ}$ 18824, febrero. Disponible en:

http://www.nber.org/papers/w18824

[5] AKERLOF, G. A.; Rose, A. K.; YELLEN, J. L. y HESSENIUS, H. (1991). «East Germany in from the cold: The economic aftermath of currency union". Brookings Papers on Economic Activity, $\mathrm{n}^{\circ} 1$, pp. 1-87. Disponible en: http://www.brookings.edu/ /media/ projects/bpea/1991-1/1991a_bpea akerlof_rose_yellen_hessenius_dornbusch_ guitian.pdf

[6] AKERLOF, G. A. y KRANTON, R. E. (2000). «Economics and Identity». Quarterly Journal of Economics, agosto, pp. 715-753. Disponible en: http://public.econ.duke.edu/ rek8/ economicsandidentity.pdf

[7] AKERLOF, G A. y KRANTON, R. E. (2002). «Identity and schooling: Some lessons for the economics of education». Journal of Economic Literature; diciembre 2002; vol. 40, $\mathrm{n}^{\circ} 4$, pp. 1167-1120. Disponible en:

http://public.econ.duke.edu/ rek8/identity\& schoolingsomelessons.pdf

[8] AKERLOF, G. A. y KRANTON, R. E. (2010). Identity Economics: How Our Identities Shape Our Work, Wages, and Well-Being. Princeton University Press.

[9] BLIEN, U.; MÖLLER, J. ; HONG VAN, P.T. y BRUNOW, S. (2016). «Long-Lasting Labour Market Consequences of German Unification». Journal of Economics and Statistics
Jahrbücher für Nationalökonomie und Statistik, vol. 236, $\mathrm{n}^{\circ}$ 2, pp. 181-216. Disponible en: http://www.degruyter.com/dg/viewar ticle.fullcontentlink:pdfeventlink/\$002fj\$002fjb nst.2016.236.issue-2\$002fjbnst-20151013\$002fjbnst-2015-1013.pdf?format

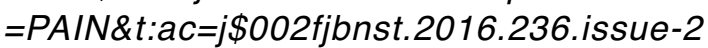
\$002fjbnst-2015-1013\$002fjbnst-20151013.xml

[10] BOERI, T. (2009). "Setting the Minimum Wage». IZA DP n० 4335, julio. Disponible en: http://ftp.iza.org/dp4335.pdf

[11] BOERI, T. (2014). «Two-Tier Bargaining». IZA DP, $\mathrm{n}^{\circ}$ 8358, julio. Disponible en: http://ftp. iza.org/dp8358.pdf

[12] BOERI, T. (2015). «Perverse effects of two-tier wage bargaining structures». IZA World of Labor 101. Disponible en: http://wol.iza.org/ articles/perverse-effects-of-two-tier-wagebargaining-structures-1.pdf

[13] BOFINGER, P. (2015). "German wage moderation and the EZ Crisis». VOX CEPR's Policy Portal, 30 de noviembre. Disponible en: http://www.voxeu.org/article/german-wagemoderation-and-ez-crisis

[14] BONESMO FREDRIKSEN, K. (2012). « Income Inequality in The European Union». Economics Department Working Papers $\mathrm{n}^{\circ}$ 952, ECO/WKP(2012)29, 16 de abril de 2012. Disponible en: http://www.oecd.org/officialdocu ments/publicdisplaydocumentpdf/?cote $=E C O$ MKP(2012)29\&docLanguage $=E n$

[15] BROADBERRY, S. N. (1998). «How Did the United States and Germany Overtake Britian? A Sectoral Analysis of Comparative Productivity Levels, 1870-1990». The Journal of Economic History, vol. 58, n 2, pp. 375-407, junio de 1998. Disponible en:

http://dx.doi.org/10.1017/S00220507 00020556

[16] CALMFORS, L. y DRIFFILL, J. (1988). «Bargaining Structure, Corporatism and Macroeconomic Performance». Economic Policy, vol. 3, n. 6, pp. 13-61, (abril).

[17] CALMFORS, L. (2013). «Sweden - From Macroeconomic Failure to Macroeconomic Success», en Maguire, M. \& Wilson, G. (eds), Business and Government, vol. 4, Challenges and Prospects, Routledge. VP: CESifo WP: Fiscal Policy, Macroeconomics and Growth: 3790). Disponible en: http://www.econstor.eu/ bitstream/10419/57944/1/71558359X.pdf

[18] CCNCC (2004). La negociación colectiva en Europa. Comisión Consultiva Nacional de Convenios Colectivos, MTAS. 
[19] CHANDLER, J.R. y ALFRED D. (1990). Scale and Scope: The Dynamics of Industrial Capitalism. Cambridge, Massachusetts: Harvard University Press.

[20] DRIFFILL, J. (2005). "The Centralization of Wage Bargaining Revisited. What have we learned?». Seminar at The European Institute, LSE, in the series Landmarks in the Political Economy of European Integration Revisited, 28 de noviembre. Disponible en: http://www.ems.bbk.ac.uk/faculty/driffill/re search/corp_paper_b.pdf

[21] DUFRESNE, A. (2002). «Wage Co-ordination in Europe: Roots and Routes», en Pochet, P. (ed.) Wage Policy in the Eurozone. Brussels, Vienna: PIE Lang, pp.79-110.

[22] EHRKE, M. (2000). «La Tercera Vía y la Socialdemocracia Europea". Disponible en: http://library.fes.de/pdf-files/bueros/chi le/01897.pdf

[23] ERNE, R. (2008). European Unions: Labor's Quest for a Transnational Democracy, Cornell University Press, 2008 («The German case»: p. 99 y ss.).

[24] ESPINA, A. (1978). «Cambios de estructura y crecimiento de la productividad en la economía española, 1964-1978", en Seminario sobre productividad y política de empleo, Ministerio Economía, Madrid, noviembre 1979, (pp. 191216). Disponible en: http://imagenesbi bliotecacentral.minhap.gob.es/pdfpublicaciones/Lit eraturagris/cambios_estructura_y_crecimien to_productividad.pdf

[25] ESPINA, A. (Comp.) (1991). Concertación social neocorporatismo y democracia. MTSS, colección Economía y Sociología del Trabajo. Disponible en: http://imagenesbibliotecacentral.minhap.gob.es/pdfpublicaciones/Literatu ragris/concertacion_social_es.pdf

[26] ESPINA, A. (2002). «La sociología del bienestar de Gösta Esping - Andersen y la reforma del estado de bienestar en Europa», febrero. Disponible en: http://imagenesbibliotecacen tral.minhap.gob.es/pdfpublicaciones/Literatura gris/ la_sociología_del_bienestar_de_gosta_ esping_andersen.pdf

[27] ESPINA, A. (2007). "La vuelta del "hijo pródigo" y la integración europea: el estado de bienestar español en el camino hacia la Unión Económica y Monetaria». Política y sociedad, monográfico: Política Social y Estado del Bienestar, vol. 44, $\mathrm{n}^{\circ}$ 2, pp. 45-67. Disponible en: http://revistas.ucm.es/index. php/POSO/article/view/POSO0707230045A
[28] ESPINA, A. (2010). "La "Década Maravillosa" y la Recesión Global de 2007-2009 (I-II)", Documentos Instituto de Estudios Fiscales: IEF Doc 2\%10; 201 pp. Disponible en: http://www. ief. es/documentos/recursos/publicaciones/ documentos_trabajo/2010_02.pdf

[29] GERLING, K. (2002). Subsidization and Structural Change in Eastern Germany, Springer Science \& Business Media, 20 de junio.

[30] GLASSNER, V. y POCHET, P. (2011). «Why trade unions seek to coordinate wages and collective bargaining in the Eurozone: past developments and future prospects». ETUI Working Paper 2011.03. Disponible en: http:// www.etui.org/Publications2/WorkingPapers/Why-trade-unions-seek-to-coordina te-wages-and-collective-bargaining-in-theEurozone

[31] GORTON, G. Y ORDONEZ, G. (2016). «Good Booms, Bad Booms». NBER Working Paper 22008, febrero. Disponible en: $h t t p: / / w w w$. nber.org/papers/w22008.pdf

[32] GRANT, O. (2005). Migration and Inequality in Germany 1870-1913, Oxford Historical Monographs, Clarendom Press.

[33] KEMMERLING, A. y BRUTTEL, O. (2006). "New politics"» in German labour market policy?. The implications of the recent Hartz reforms for the German welfare state». West European Politics, vol. 29, $\mathrm{n}^{\circ}$ 1, pp. 90-112, versión previa disponible en: https://www.wzb. eu/www2000/alt/ab/pdf/dp_sp_i_2005-101. $p d f$

[34] KINDLEBERGER, C.P. (1967). Europe's Postwar Growth: The Role of Labor Supply, Oxford University Press.

[35] KING, R. (2012). «Theories and Typologies of Migration: An Overview and a Primer», Willy Brandt S. of W.P. in International Migration and Ethnic Relations $n^{\circ} 3 / 12$. Disponible en: https://www.mah.se/upload/Forskningscentrum /MIMNB/WB\%203.12.pdf

[36] KOLLMANN, R.; RATTO, M.; ROEGER, V.; IN'T VELD, J. y VOGEL, L. (2014). «What drives the German current account? And how does it affect other EU member states?» European Economy Economic Papers, $n^{\circ} 516$, abril. Disponible en: http://ec.europa.eu/eco nomy_finance/publications/economic_paper/ 2014/pdf/ecp516_en.pdf

[37] KRUEGER, A.B. y PISCHKE, J.S. (1995). «A Comparative Analysis of East and West German Labor Markets: Before and After $D$ 
Unification», en Freeman-Katz (1995). pp. 405-446. Disponible en: http://www.nber.org/ chapters/c7864

[38] LASH, S. y URRY, J. (1987). The End of Organized Capitalism. Cambridge: John Wiley \& Sons.

[39] LEHMANN, H. (2003). «Wage Increases are no "Productivity Whip": An Analysis of the East German Manufacturing Sector». Wirtschaft im Wandel, vol. 9, $\mathrm{n}^{\circ} 1,15$ enero. Disponible en: http://www.iwh-halle.de/asp/ pubdetails. asp? Lang $=e \& I D=1059 \& A C T I O N=$ Details

[40] MAIER, CH. S. (1988). La refundación de la Europa burguesa. Estabilización en Francia, Alemania e Italia en la década posterior a la Primera Guerra Mundial, MTSS, Colección historia social, $788 \mathrm{pp}$.

[41] MARCOVITS, A. S. (1988). La política de los sindicatos en Alemania Occidental. Estrategias de clase y representación de intereses durante el crecimiento y la crisis, MTSS, col. Economía del trabajo, 1988 (primera edición en inglés, de Cambridge U.P., en 1986).

[42] MARCOVITS, A.S. y OTTO. A. (1991). «Los sindicatos alemanes y la Europa de 1992, en Espina», en A. (Comp.) (1991), pp. 163-190.

[43] MÜLLER, S. Y STEGMAIER, J. (2015). «The Dynamic Effects of Works Councils on Labor Productivity: First Evidence from Panel Data». IWH Discussion II Papers, n014/2015, septiembre. Disponible en: http://www.iwh-halle. de/d/publik/disc/14-15.pdf

[44] NORBERG, P. y NUMHAUSER-HENNING, A. (2004). "La Negociación Colectiva en Suecia», en CCNCC (2004), pp. 235-266

[45] OECD (2015). OECD Employment Outlook 2015.

[46] PARICIO TORREGROSA, J (1985). «Características de la dinámica de los salarios industriales», en Lluis Fina Sanglas, Alvaro Espina Montero (coords.) Estudios de economía del trabajo en España, vol. 2 (Salarios y política de rentas), pp. 535-550.

[47] SCHMITT, J. (2013). «Why Does the Minimum Wage Have No Discernible Effect on Employment?», febrero. CEPR: http://www. cepr.net/documents/publications/min-wage2013-02.pdf

[48] SCHMITTER, P.C. (1974). «Still the Century of Corporatism?». The Review of Politics, vol. 36, $\mathrm{n}^{\circ}$ 1, The New Corporatism: Social and Political Structures in the Iberian World (enero), pp. 85-131, Disponible en: http://www.roche Ileterman.com/ComparativeExam/sites/defaul t/files/Bibliography\%20and\%20Summaries/ Schmitter\%201974.pdf
[49] SCHMITTER, P.C. Y GROTE, J.R. (1997). «The Corporatist Sisyphus: Past, Present and Future»- European University Institute, Dep. of Pol. an Soc. Sciences Working Paper SPS, $n^{\circ}$ 97/4: Disponible en: http://cadmus.eui.eu/ bitstream/id/986/97_4.pdf/1997

[50] SCHULTEN, T. (2002). «Europeanisation of Collective Bargaining. An Overview on Trade Union Initiatives for a Transnational Coordination of Collective Bargaining Policy", WSI Discussion Paper $n^{\circ}$ 101, Düsseldorf, mayo. Disponible en: http://www.boeckler.de/ pdf/p_wsi_diskp_101.pdf

[51] SENGENBERGER, W. (1988). «La política de empleo en Alemania Occidental: restaurar la competencia entre los trabajadores", en W. Sengerberger, Lecturas sobre el mercado de trabajo en la RFA, II, MTSS, Col. Economía del Trabajo.

[52] SENGENBERGER, W. (1991). "Cambios recientes en la organización industrial y sus consecuencias para el diálogo social y la cooperación», en A. Espina (Comp.) (1991).

[53] SHIMER, R. y WERNING, I. (2006). «Reservation Wages and Unemploymentl nsurance». NBER Working Paper 12618, octubre. Disponible en: http://www.nber.org/ papers/W12618

[54] SINN, H.W. (2007). Can Germany Be Saved?: The Malaise of the World's First Welfare State, MIT press. Especialmente Capítulo V: «The Withering East».

[55] SONG, J.; PRICE, D. J.; GUVENEN, F.; BLOOM, N. y VON WACHTER, T. (2015). «Firming Up Inequality». NBER Working Paper 21199, mayo. Disponible en: http://www.nber.org/ papers/ w21199

[56] STREECK, W. (2008). «Industrial Relations Today: Reining in Flexibility». MPIfG Working Paper 08/3, Köln. Disponible en: http://www. mpifg.de/pu/workpap/wp08-3.pdf

[57] STREECK, W. (2008b). Re-Forming Capitalism: Institutional Change in the German Political Economy, OUP Oxford , 18 diciembre.

[58] STREECK, W. (2014). Buying Time: The Delayed Crisis of Democratic Capitalism, Verso (1 de mayo).

[59] STREECK, W. (2016). How Will Capitalism End, Verso Books (8 de noviembre).

[60] WINDOLF, P. (1989). «Productivity Coalitions and the Future of European Corporatism", Industrial Relations. vol. 28, $n^{\circ} 1$. Disponible en: https://www.uni-trier.de/fileadmin/fb4/prof/ SOZ/APO/1-001.pdf

[61] ZACHERT, U. (2004). «La negociación colectiva en Alemania», en CCNCC (2004), pp. 29-52. 